\title{
A Numerical Study on Effects of Randomly Distributed Subsurface Hydrogen Pores on Fretting Fatigue Behaviour of Aluminium AlSi10Mg
}

\author{
Reza Talemi \\ Department of Materials Engineering, KU Leuven, 3001 Leuven, Belgium \\ reza.hojjatitalemi@kuleuven.be
}

\begin{abstract}
The successful construction of additively manufactured metallic components for safety-critical applications requires a thorough understanding of the associated tribo-mechanical properties such as fretting fatigue phenomenon. Various porosity formations mechanisms occur in selective laser melting of aluminium alloys. The internal porosity is forming because of the powder and printing process itself. These pores, which act as internal micro defects, result in premature fatigue crack initiation and subsequent fatigue failure. In this study, numerical simulation technique is used to investigate the effects of randomly distributed hydrogen pores on the fretting fatigue response of additively manufactured aluminium AlSi10Mg part. From the simulation results it has been found that at the high-stress levels the fretting fatigue primary variables such as tangential and frictional shear stresses along with slip amplitude are slightly affected by the distribution of porosity close to the contact interface. $60 \%$ of the fatigue crack initiation locations are detected at the pore sites (killer defects) underneath the contact interface near the contact edge. The killer defect size varies between $32 \mu \mathrm{m}$ to $60 \mu \mathrm{m}$ in diameter. Eventually, the fretting fatigue lifetime decreases for $92 \%$ of simulated case studies and higher scatter results are observed at the high-stress levels compared to the low stresses.
\end{abstract}

Keywords: Fretting fatigue, Numerical Modelling, Additive Manufacturing, Metals, AlSi10Mg.

\section{Introduction}

Additive manufacturing (AM) is becoming a game-changing technology with enormous potential impact on the range of available designs, enabling new component capabilities that cannot be realized with any other technology and reducing lead-times, storage and transportation costs. Among different available AM technologies, Selective Laser Melting (SLM) is a powder-bed based technique which is very popular. Molitch-Hou [1] has reported seven different issues that could occur during the printing process of AM parts using the SLM technique. These issues are listed as 
density, cracking, warping, surface finish, internal residual stress, porosities and other issues such as swelling or melt balling. Among these challenging issues, hydrogen porosity results in a density loss, as investigated in [2]. The existence of porosities is because of formation of micro-level cavities within the body of an AM component. The origin of porosity forming could be because of the powder and the printing process itself. These internal micro defects form an internal microcrack which propagates under fatigue loading conditions up to the premature failure of the part.

According to Kempen et al. [3], the formation of the gas pores during the SLM process is the result of entrapped gases. Hot-extraction analysis is used to measure the amount of hydrogen in powder. Weingarten et al. [2] have shown the moisture of powder can evaporate by heating it up to the solidus temperature. They have also found that a density loss of more than $10 \%$, which is caused by the gas pores, is achievable by changing different process parameters such as build-up, laser beam diameter, and the build-up layer thickness. In general, these hydrogen porosities, which are cracklike voids, within the sample can act as strong stress raisers and, in particular, when subjected to cyclic fatigue loading conditions, results in premature fatigue failure [4].

The successful construction of additively manufactured metallic components for safety-critical applications requires a thorough understanding of metallurgical structures, residual stresses and associated mechanical properties. Fatigue fracture assessment of SLM components is welldocumented in the literature [5-8]. However, according to the author's best knowledge, there is no research work focusing on tribo-mechanical properties, such as fretting fatigue phenomenon, of SLM parts. By definition, the fretting fatigue occurs when two contacting parts slip over each other at a micro level while being subjected to an external fatigue loading conditions [9], which happens in many industrial applications such as automotive parts [10], fasteners [11], bearings shafts [12], steam and gas turbines' blades [13]. Many of these applications such as bearings shafts, steam, gas turbines are potential applications for AM technology. When compared to a plain fatigue problem, fretting fatigue reduces the lifetime of the part by half [14]. Therefore, correct assessment of the fretting fatigue lifetime is very important for safety-critical applications.

Romano et al. [15] have reported that the presence of the subsurface porosity is one of the challenging properties of as-built AM parts. The dramatic reduction in fatigue strength of AM components is explained due to the as-built surface, which should be improved using corrective machining process as suggested in [16]. Knowing all these challenges, in order to bring the AM technology to the industrial level, it is necessary to understand the performance of AM 
manufactured components when subjected to complex tribo-mechanical loadings such as the fretting fatigue loading conditions. The fretting fatigue phenomenon is a complicated task, because of the fact that the contact stresses at the contact interface are multiaxial. To this end, depending on the multiaxiality and non-proportionality of the stresses at the contact interface, the response of the materials when subjected to the fretting fatigue loading conditions is different, as reported in [1719]. In this study, numerical simulation method has been used to address the effects of the hydrogen porosity on the fretting fatigue behaviour of SLM aluminium AlSi10Mg part. To this end, finite element models are set up to study the effects of randomly distributed subsurface pores on the fatigue and fretting fatigue response of the SLM manufactured parts. The developed models are used to extract the stress components and monitor the possible local stress concentrations at the pore sites. The fretting fatigue primary parameters such as slip amplitude, tangential and frictional shear stresses are compared against a homogeneous model. Furthermore, continuum damage mechanics is employed to estimate the fatigue and fretting fatigue lifetimes. Next, the numerically estimated lifetimes obtained from a series of models, using the random distribution of the subsurface hydrogen pores, are compared against the homogeneous model.

\section{SLM process and fatigue assessment}

During the SLM process AM parts are fabricated layer after layer using a laser beam on a powder bed which results in melting and consequently solidification of the powders. The SLM method is currently popular for the manufacturing of metallic parts $[15,16]$. The defects induced by the SLM method are namely, gas pores and imperfections, as reported in [2]. Wiengarten et al. [2] have shown the powders which are not completely melted are the main cause of the imperfections. The formation of a gas pore in the SLM process could be due to lack of fusion, rayleigh instability, overheating, melt pool dynamics and external influences [20]. Aboulkhair et al. [21] have categorized the SLM porosity to metallurgical and keyhole pores. According to their findings, the metallurgical pores are very small with approximately maximum radius of $100 \mu \mathrm{m}$ and have a spherical shape. In contrary, the keyhole pores are bigger in size (larger than $100 \mu \mathrm{m}$ ) and have a random and irregular shape. They have reported that the metallurgical pores are evolved from the powder during consolidation or created at slow scanning speeds from gases trapped within the melt pool [21]. They reported that the rapid solidification of the metal without complete filling of gaps with molten metal results in a keyhole shape pores [22]. It has been reported by Wiengarten et al. [2] that approximately $96 \%$ of the gas content in the voids, during the SLM process for the 
AlSi10Mg alloy, is hydrogen and they identified the spherical pores as hydrogen pores. Furthermore, according to their study, the main dominating hydrogen source was the moisture of the powder's particles. This moisture could be lowered by a drying process. However, the process is limited by the sintering temperature of the powder.

The physical mechanism of pore formation and growth during the SLM process has been comprehensively explained by Wiengarten et al. [2]. Here the main aspects of this process are elaborated for the sake of completeness. Figure 1(a) schematically represents the pore formation mechanism. The powder laying on the powder bed absorbs energy by moving the laser beam along the scanning direction. This results in the formation of a melt pool which is deeper than the deposited layer's thickness. As a consequence, a metallurgical bonding between the new layer and previously deposited layer is formed. The solid-liquid interface consists of a solidification front and melting front, as shown in Figure 1(a). Nucleation of the gas porosity occurs by reaching the local solubility limit of the melt. The hydrogen porosities initiated at the melting front move to the melt pool surface. This upward movement of the pores results in declining hydrogen content of the solidified layer. In contrary, the hydrogen pores initiated at the solidification front cannot move up due to the short time between the pore initiation and being captured by the solidification front which stopes the pore's growth, as elaborated in [2].

Fatigue response of metallic materials manufactured using the SLM method is currently not well understood [23]. In fact, the observed experimental fatigue results show a large scatter because of the presence of surface and subsurface defects, such as hydrogen pores [24]. According to studies in the literature, as-built components show a considerable fatigue lifetime reduction, which could reach the order of $40 \%$ for the SLM technique [25]. This reduction in fatigue lifetime is directly linked to surface and subsurface defects. Even the presence of a single micro-level pore influences the fatigue response of the as-built AM part. Figure 1(b) illustrates the CT scan of AlSi10Mg alloy, which is manufactured using the SLM method and confirms the significant presence of the subsurface pores. As depicted the large pore density near the surface of the part forms a dangerous cluster of defects which explains why the fatigue strength of such a component drops drastically [23].

Figure 1 (a) Schematic view of hydrogen pores formation and growth during the SLM process [2] and (b) a cluster of subsurface pores in AISi10Mg part manufactured using the SLM technique [23]. 
It is well known that the SLM process parameters have a significant effect on the fatigue response of as-built AM parts [8, 20, 24]. Romano et al. [24] have used the fracture mechanics approach to investigate the relationship between the material quality of SLM manufactured parts and fatigue strength. They used three different processes (P1, P2 and P3) to study the influence of defect content in SLM parts and their fatigue limit using Kitagawa diagram. In this study their observed fatigue data are used to calibrate and validate the developed model for estimating the fatigue lifetime which is elaborated later in next section.

\section{Continuum damage mechanics}

In this work, a continuum damage mechanics approach is used to estimate the lifetime of the SLM manufactured AlSi10Mg parts subjected to cyclic tribo-mechanical loading conditions. Damage mechanics explains the materials' degradation when subjected to different loading conditions. To do so, a damage parameter, $\mathrm{D}$, is defined to address the effects of micro and macro scale damages on the mechanical response of materials. The damage variable is generally defined as a tensor, however; by assuming isotropic damage, $D$ can be considered as a scalar variable.

The physical meaning of damage evolution law is based on the thermodynamic principles. By increasing the number of fatigue cycles due to accumulation of damage induced by micro-voids, such as pores in this research, the material has sufficiently degraded and the continuity of material is lost at a micro scale. Kachanov [26] has defined a scaler damage parameter in a damaged material by introducing a Representative Volume Element (RVE). He has reported that under uniaxial loading conditions, the most damaging plane is perpendicular to the axial loading direction. By definition, the damage variable $D$ can be defined as:

$$
D=\frac{\delta S-\delta \tilde{S}}{\delta S}=\frac{\delta S_{D}}{\delta S}
$$

where $\delta S$ is the intersection area, $\delta \tilde{S}$ is defined as the effective area of resistance, $\delta \tilde{S}<\delta S$, and $\delta S_{D}$ is the total area of defects. The stress concentration is at the geometric discontinuities between the micro-cracks and cavities. Then according to these definitions, $D=0$ corresponding to the undamaged state and $D=D_{c}$, where $D_{c}$ is a critical damage value, corresponding to the rupture of the RVE in two parts which represent a fully damaged material. Then the effective stress, $\tilde{\sigma}$, on the damaged material can be defined as 


$$
\tilde{\sigma}=\frac{\sigma}{1-D}
$$

Evidently, $\tilde{\sigma} \geq \sigma, \tilde{\sigma}=\sigma$ for undamaged material and $\tilde{\sigma} \rightarrow \infty$ at the moment of fully damaged material i.e. onset of macro crack initiation. The elasticity modulus of the damaged material can be written as

$$
\tilde{E}=E(1-D)
$$

$E$ is the modulus of elasticity of the undamaged material, $\tilde{E}$ represents the elastic modulus of the damaged material which drops as the fatigue cycles increases. (1-D) is defined as the damage parameter which can be written as

$$
\sigma=(1-D) E \varepsilon
$$

Micro-mechanical damage mechanism is used to define constitutive equations which address the damage accumulation of materials subjected to different loading conditions, such as fatigue damage [27]. In the case of high cycle fatigue, which is applicable for this study, the damage accumulation is defined as [27]

$$
\frac{d D}{d N}=\left[\frac{\sigma_{a}}{\sigma_{r}(1-D)}\right]^{m}
$$

where

$$
\sigma_{r}=\sigma_{0}\left(1-k \frac{\sigma_{m}}{\sigma_{u}}\right)
$$

where $\sigma_{a}, \sigma_{m}$ and $N$ are the stress amplitude, mean stress and the number of fatigue cycles to failure, respectively. $\sigma_{0}, k, m$, and $\sigma_{u}$ (ultimate stress) are material constants, as described by Lemaitre [28], which are obtained experimentally. $\sigma_{r}$ is resistance stress as it is the material parameter that resist against the fatigue damage accumulation as elaborated in [29]. $\sigma_{r}$ is function of $\sigma_{m}$, as can be seen from the Equation (6), and is equal to $\sigma_{0}$ in case of fully reversed fatigue loading conditions $\left(R_{\mathrm{s}}=0\right)$ in which the mean stress is zero $\left(\sigma_{m}=0\right)$.

In this investigation the experimental $S-N$ data available in the literature are used to estimate the material constants, $\sigma_{r}$ and $m$ needed in Equation (5), as also employed successfully in [30]. The $S$ $N$ curve for a full reversal fatigue loading conditions in form of a power-law fit is written as 


$$
\sigma_{a}=\dot{\sigma}_{f}(N)^{b}
$$

where $N$ is the number of fatigue cycles required to failure at the stress amplitude $\sigma_{a}, \hat{\sigma}_{f}$ and $b$ are material constants. In this study, the fatigue experimental data reported by Romano et al. [24] have been used to calculate the material constants. Figure 2 shows the S-N curve for AlSi10Mg alloy which results in $\dot{\sigma}_{f}=552.68 \mathrm{MPa}$ and $\mathrm{b}=-0.075$.

Figure $2 S-N$ curve reported by Romano et al. [24] has been used for AlSi10Mg material when subjected to fully reversed fatigue loading conditions. A power law curve is fitted to the experimental data.

Therefore, Equation (5) can be integrated from the undamaged material, i.e. $D=0$, to the fully damaged material, i.e. $D=D_{c}$. In this study fully damaged condition is corresponding to the number of fatigue cycles to failure $N_{f}$. Considering the fully reversed loading conditions, Equation (5) yields

$$
\begin{gathered}
\int_{0}^{N_{f}} d N=\int_{0}^{N_{f}}\left\{\frac{\sigma_{0}(1-D)}{\sigma_{a}}\right\}^{m} d D \\
N_{f}=\left[\frac{\sigma_{0}}{\sigma_{a}}\right]^{m}\left(\frac{(1-D)^{m+1}}{-(m+1)}\right)_{0}^{1} \\
N_{f}=\frac{1}{(1+m)}\left[\frac{\sigma_{0}}{\sigma_{a}}\right]^{m} \\
\sigma_{a}=\frac{\sigma_{0}}{(1+m)^{\frac{1}{m}}} N_{f}^{-\frac{1}{m}}
\end{gathered}
$$

By comparing Equations (7) and (11) results in

$$
\begin{gathered}
-\frac{1}{m}=b, \quad \frac{\sigma_{0}}{(1+m)^{1+m}}=\dot{\sigma}_{f} \\
m=-\frac{1}{b}=14.29, \quad \sigma_{0}=\sigma_{f}\left(1-\frac{1}{b}\right)^{-b}=632.6 \mathrm{MPa}
\end{gathered}
$$

By substituting Equation (13) in Equation (9) the number of cycles to failure can be written as 


$$
N_{f}=\frac{1}{15.29}\left[\frac{632.6}{\sigma_{a}}\right]^{14.29}
$$

Equation (14) is used to estimate the fatigue and fretting fatigue lifetime of the SLM parts investigated in this study. It is worth mentioning that the maximum in-plane principal stress amplitude is considered as the damaging stress in this work.

\section{Finite element model of fretting fatigue contact}

\subsection{Modelling randomly distributed subsurface hydrogen pores}

In this study the hydrogen pores are only distributed underneath the contact line for simulating the fretting fatigue problem. For the homogeneous contact problem, a fretting pad with a radius of $50 \mathrm{~mm}$ is pushed against a fatigue specimen which results in a maximum contact pressure of $199 \mathrm{MPa}$ and a contact width of $320 \mu \mathrm{m}$, which are measured using the developed finite element model. More information about the model is provided in the fretting fatigue modelling section. Python programming language in combination with ABAQUS software is used to create the random distribution of the subsurface hydrogen pores. Figure 3 illustrates the finite element mesh and the cluster of defects which are randomly distributed underneath the surface at a distance of $35 \mu \mathrm{m}$ and the pore size varies between $10 \mu \mathrm{m}$ to $70 \mu \mathrm{m}$ in diameter, as measured and reported in [24]. An RVE is considered with a size equal to two times the semi-contact width of the fretting fatigue contact problem (i.e. $2 a=320 \mu \mathrm{m}$ ). The main reason for selecting this value is simply because of the fact that the stresses underneath the contact are only affected up to a distance equal to the contact width. Using this RVE size, the void volume fraction of the hydrogen porosities is approximately $5 \%$ for all simulations.

\section{Figure 3 Random distribution of pores in a finite element mesh with a void volume fraction of approximately $5 \%$ in a $320 \mu \mathrm{m}$ RVE.}

The fatigue model has been set up to validate the developed damage model based on the experimental data reported in the literature [24] which is plotted in Figure 2. Figure 4(a) shows a two-dimensional finite element model for simulating the fatigue specimen and the random distributions of the subsurface pores. The modelled fatigue specimen has length, width and 
thickness of $13 \mathrm{~mm}, 2.5 \mathrm{~mm}$ and $2.5 \mathrm{~mm}$, respectively. Only half of the specimen is simulated due to symmetry boundary conditions. The hydrogen pores are only distributed at the centre of the fatigue specimen. Nine different cyclic fatigue stress levels are simulated ranging from $77 \mathrm{MPa}$ to $135 \mathrm{MPa}$ at a stress ratio of -1 . For each fatigue stress level, five different pore distributions are simulated which results in total 45 simulations, namely DF1 to DF45.

Aluminium AlSi10Mg, as reported in [2], is used for the fatigue sample with Young's modulus, yield stress, ultimate strength and Poisson's ratio of $E=70 \mathrm{GPa}, \sigma_{y}=240 \mathrm{MPa}, \sigma_{u l t}=460 \mathrm{MPa}, \vartheta=$ 0.3 , respectively. A 2D, 4-node (bilinear), plane strain quadrilateral, reduced integration element (CPE4R) is used to mesh the fatigue specimen. A minimum mesh size of $10 \mu \mathrm{m} \times 10 \mu \mathrm{m}$ is achieved at the centre of the specimen which is declined gradually to approximately $1 \mathrm{~mm}$ far from the specimen's centre.

\subsection{Fretting fatigue model}

To simulate the fretting fatigue problem, as shown in Figure 4(b), a 2D finite element model has been set up. AlSi10Mg with properties elaborated in the above section is assigned to both the fretting pad and the fatigue specimen. The model is meshed using the same element as described for the fatigue model with a minimum mesh size of $10 \mu \mathrm{m}$ at the contact line. The random hydrogen pores are distributed within the fatigue sample underneath the contact line.

Figure 4 (a) loading and boundary conditions of the fatigue finite element model with a random distribution of subsurface hydrogen porosities and (b) mesh, loading and boundary conditions which are used for the fretting fatigue model.

A master-slave algorithm, available in Abaqus software, is used to set up the contact between the pad and the specimen by assigning the slave and master surfaces to the curved surface of the pad and the top surface of the specimen, respectively. To simulate the frictional behaviour of the contact, a Lagrange multiplier formulation, which is also available in Abaqus, is used with a friction coefficient of $\mu=0.5$. This value has been chosen as an arbitrary value since the main goal of the fretting fatigue model is comparing the homogeneous model against the non-homogeneous ones with pores. 
The specimen has a length of $50 \mathrm{~mm}$, a width of $2 \mathrm{~mm}$ and a thickness of $10 \mathrm{~mm}$. The fretting pad has a radius of $50 \mathrm{~mm}$ with a thickness which is equal to specimen's thickness, i.e. $10 \mathrm{~mm}$. Symmetric boundary conditions are applied to the bottom edge of the fatigue specimen, axial centreline, which restricts the specimen moving along the Y-direction. The left side of the fatigue specimen is allowed only to move along the Y-direction. To apply the tangential load, $Q$, a coupling constraint is set up between a reference point, which the load is applied to, and the edge of the fretting pad. To apply both the fretting and the fatigue loading conditions, first a contact load of $120 \mathrm{~N}$ is applied at the top surface of the fretting pad which is kept constant during the simulation. Then the cyclic axial fatigue stress, ranging from 50MPa to 90MPa with a stress ratio of -1 , and a tangential load of $20 \mathrm{~N}$ are applied simultaneously with a phase shift of $90^{\circ}$ which leads to an in-phase stress distribution at the contact interface.

As mentioned above, to assess the possible influence of hydrogen pores on the fretting fatigue contact problem, random pores are distributed within the specimen and only underneath the contact line at a distance of $2 a=320 \mu \mathrm{m}$. Same as the fatigue model, five different pore distributions are simulated for each axial fatigue load level. In total, 25 models are simulated for the fretting fatigue contact problem with 25 unique pore distributions, namely D1 to D25, as depicted in Figure 5.

Figure 525 fretting fatigue contact models with different hydrogen pores distributions D1 to D25.

\section{Results and discussions}

\subsection{Fatigue lifetime estimation and model validation}

Figure 6 compares the 45 estimated fatigue lives at nine different stress levels against an experimental curve fitted in the fatigue data reported for Aluminium AlSi10Mg parts manufactured using the SLM technique [24]. The estimated fatigue lives are in good correlation with the experimental data for all stress levels. As can be noted, the estimated results reproduce the scattering nature of the fatigue data, which are typically observed experimentally.

Figure 6 Comparing numerically estimated fatigue lifetime with an experimental curve fitted in fatigue data reported for Aluminum AISi10Mg parts manufactured using the SLM technique [24]. 
Figure 7 (a) to (d) shows contour plots of maximum principal stress for four different simulations at the high and low-stress levels, namely DF1 and DF3 at 155MPa, DF40 and DF45 at 270MPa, as indicated in Figure 6. Interestingly, from the obtained results, it has been observed that for all simulations the fatigue cracks initiate at the subsurface pore sites with different sizes and the killer defect is not always the biggest pore. It has been detected that the location of the fatigue crack is more affected by the way the subsurface hydrogen pores are distributed within the fatigue specimen rather than its size. As indicated in Figure 7, the maximum stress value is not always at the pore site which is close to the surface and it varies randomly depending on the random distribution of the cluster of defects. These findings explain the inherent fatigue scatter which is strongly linked to the manufacturing process. Moreover, the obtained results validate the developed fatigue damage model used in this study.

\section{Figure 7 Contour plots of maximum principal stress for four different fatigue models at two stress} levels, namely DF1 and DF3 at 155MPa, DF40 and DF45 at 270MPa. The results show that the killer defect is not always the biggest hydrogen pore and the location of the fatigue crack initiation is more affected by the pore distribution rather than its size.

\subsection{Fretting fatigue lifetime estimation}

The main objective of this research work is understanding the effects of the randomly distributed subsurface hydrogen pores on the fretting fatigue primary parameters and eventually the fretting fatigue lifetime. To do so, in the first step, a homogeneous fretting fatigue model has been set up which is considered as a reference simulation in this work. Figure 8 (a) to (c) shows the maximum principal stress distribution at maximum, mean and minimum loading time steps for the homogeneous model, respectively, at axial fatigue stress of $80 \mathrm{MPa}$. As can be seen, for all loading steps, the maximum stress happens to occur at/near the contact edge. Nevertheless, it is evident that the location of the maximum stress is not fixed during all loading steps and moves from leading edge to trailing edge, as also reported in the literature [9, 18, 19, 31-34]. 
Figure 8 Maximum in-plane principal stress contour plots for the homogenous fretting fatigue model at maximum, mean and minimum loading time steps for $80 \mathrm{MPa}$ axial stress. The stress distributions show that the location of the maximum stress is not fixed during all loading steps and moves from leading edge to trailing edge.

Figure 9 (a) to (c) shows the maximum principal stress distribution at maximum, mean and minimum loading time steps for an axial stress range of 80MPa for the non-homogenous fretting fatigue contact model (D16). From the figure, it can be seen that the location of the maximum value of the maximum principal stress, which is considered here as the crack initiation location, is at the pore site for all loading steps. However, its location shifts from one pore to another depending on the loading step. By comparing Figure 8 and Figure 9, it can be reached that at the same axial stress level the crack initiation location is influenced by the distribution of the hydrogen porosities underneath the contact interface.

Figure 9 Maximum in-plane principal stress contour plots in the non-homogenous fretting fatigue model (D16) at maximum, mean and minimum loading time steps for 80MPa axial stress. The stress distributions show that the maximum principal stress's location is underneath the contact interface at the hydrogen pore site and its location varies.

Form the obtained results, it has been found that for 15 simulations $(60 \%)$ the location of the fretting fatigue crack is at the hydrogen pore (killer defect) underneath the contact interface near the contact edge as indicated by star signs in Figure 10. For 10 simulations (40\%) the fretting fatigue crack initiates at the contact interface same as the homogenous model. No influence of the axial stress has been observed on shifting the crack initiation's location from the contact interface to the hydrogen pores. At least one case is found for each of the simulated axial stresses in which the fretting fatigue crack initiates at the contact interface, as plotted in Figure 11. No particular relationship has been detected between the hydrogen pore distribution's pattern and the initial crack location and it is realized to be highly dependent on the scattering of the pores.

Figure 10 For $60 \%$ of the simulated non-homogenous cases the crack initiation sites are at the pore locations. 
Figure 11 For $40 \%$ of the simulated non-homogenous cases in which the crack initiation locations are at the contact interface between the fretting pad and the fatigue specimen.

Figure 12(a) shows the crack initiation sites for all simulated models at different stress levels. For all cases the initial crack sites are at the side of the fatigue specimen where the axial fatigue load is applied. The maximum crack initiation depth is $50 \mu \mathrm{m}$ for the majority of the case studies except for two cases at high-stress levels which the depth increases to more than $100 \mu \mathrm{m}$. The killer defect size varies between $32 \mu \mathrm{m}$ and $60 \mu \mathrm{m}$, as depicted in Figure 12(b) and no axial stress dependency has been observed. As shown in Figure 12(b), the average killer defect size of $46 \mu \mathrm{m}$ has been detected for the simulated fretting fatigue contact cases at presence of randomly distributed subsurface hydrogen porosities.

Figure 12 (a) the distribution of the crack initiation locations for all simulated non-homogenous models for all applied axial stresses ranging from 50MPa to 90MPa and (b) variation of the killer defect sizes for the fretting fatigue non-homogenous models.

Figure 13 and Figure 14 compare the tangential stress, frictional shear stress and slip distribution, extracted at the contact interface, between the reference homogenous model and the nonhomogenous ones at the low and high applied axial stresses i.e. 50MPa and 90MPa, respectively. Figure 13 (a) and (c) shows that the presence of the subsurface hydrogen pores does not affect the tangential stress and slip distributions at the contact interface for 50MPa axial stress. Nonetheless, the frictional shear stress distribution, in particular the sticking area, is slightly influenced by the presence of the subsurface pores. In contrary, for high axial stress cases the subsurface pores distributions change the stresses and the slip amplitude at the contact line. Despite all observed minor fluctuations, it can be concluded that the overall influence of the subsurface pore distributions on the fretting fatigue primary variables such as the tangential, frictional shear stresses and the slip amplitude is negligible. Moreover, for majority of these cases, in particular for high axial stresses, the crack initiation site is at the subsurface pore rather than the contact interface, which is shown by star sings in Figure 13 and Figure 14. 
Figure 13 Distributions of (a) the tangential stress, (b) the frictional shear stress and (c) the slip amplitude for 50MPa axial stress.

\author{
Figure 14 Distributions of (a) the tangential stress, (b) the frictional shear stress and (c) the slip \\ amplitude for 90MPa axial stress.
}

Figure 15 compares the estimated lifetime for all 25 simulated fretting fatigue cases against the reference homogenous model. As can be seen from the figure, the fretting fatigue lifetime drops at the presence of the subsurface hydrogen pores regardless of the location of the crack initiation. This decrease in lifetime is mainly because of the higher stress values at the location of pores or at the contact interface. The obtained results show that at the high-stress levels the lifetime reduction is considerably higher when compared to low stresses. Furthermore, the scatter data is more pronounced at the high-stress amplitudes. From the numerically estimated results it can be concluded that the fretting fatigue crack initiation lifetime declines drastically from $10^{6}$ cycles to $10^{4}$ for the high-stress levels at the presence of the subsurface hydrogen pores.

Figure 15 Comparing the estimated fretting fatigue lives between the reference (without pore) and the non-homogenous (with pores) models at different applied axial stress ranges.

\title{
6. Conclusion
}

In this study, the fretting fatigue behaviour of additively manufactured metallic component has been numerically investigated. Finite element modelling was used to understand the effects of randomly distributed subsurface hydrogen pores, manufactured by the SLM technique, on the fretting fatigue response of AlSi10Mg alloy. The simulation results reveal that the lifetime decreases for $92 \%$ of simulated case studies. Higher scatter results were observed at the high-stress levels compared to low stresses. $60 \%$ of the crack initiation sites were found at the pores (killer defects) underneath the contact interface near the contact edge. It was observed that the killer defect size varies between $32 \mu \mathrm{m}$ to $60 \mu \mathrm{m}$. At high-stress levels, the fretting fatigue parameters such as tangential stress, frictional shear stress, and slip amplitude were slightly affected by 
distribution of porosity close to the contact interface. The numerically obtained results show the importance of considering the random distribution of the subsurface hydrogen pores and their effects on the tribo-mechanical behaviour of materials manufactured using the SLM technique. For future work, the fretting fatigue response of SLM part should be examined experimentally to validate the obtained numerical results.

\section{Acknowledgement}

The author gratefully acknowledges the financial support provided by the University of Leuven (KU Leuven) under grant number STG/18/010.

\section{References}

[1] M. Molitch-Hou, "7 Issues to Look Out for in Metal 3D Printing," vol. 2017, ed, 2017.

[2] C. Weingarten, D. Buchbinder, N. Pirch, W. Meiners, K. Wissenbach, and R. Poprawe, "Formation and reduction of hydrogen porosity during selective laser melting of AlSi10Mg," Journal of Materials Processing Technology, vol. 221, pp. 112-120, 2015.

[3] K. Kempen, L. Thijs, J. Van Humbeeck, and J.-P. Kruth, "Mechanical properties of AlSi10Mg produced by selective laser melting," Physics Procedia, vol. 39, pp. 439-446, 2012.

[4] G. Kasperovich and J. Hausmann, "Improvement of fatigue resistance and ductility of TiAl6V4 processed by selective laser melting," Journal of Materials Processing Technology, vol. 220, pp. 202-214, 2015.

[5] E. Brandl, U. Heckenberger, V. Holzinger, and D. Buchbinder, "Additive manufactured AlSi10Mg samples using Selective Laser Melting (SLM): Microstructure, high cycle fatigue, and fracture behavior," Materials \& Design, vol. 34, pp. 159-169, 2012/02/01/ 2012.

[6] N. E. Uzan, R. Shneck, O. Yeheskel, and N. Frage, "Fatigue of AlSi10Mg specimens fabricated by additive manufacturing selective laser melting (AM-SLM)," Materials Science and Engineering: A, vol. 704, pp. 229-237, 2017/09/17/ 2017.

[7] N. E. Uzan, S. Ramati, R. Shneck, N. Frage, and O. Yeheskel, "On the effect of shot-peening on fatigue resistance of AlSi10Mg specimens fabricated by additive manufacturing using selective laser melting (AM-SLM)," Additive Manufacturing, vol. 21, pp. 458-464, 2018/05/01/ 2018. 
[8] S. Romano, L. Patriarca, S. Foletti, and S. Beretta, "LCF behaviour and a comprehensive life prediction model for AlSi10Mg obtained by SLM," International Journal of Fatigue, vol. 117, pp. 47-62, 2018/12/01/ 2018.

[9] R. H. Talemi, M. A. Wahab, and P. De Baets, "Numerical modelling of fretting fatigue," in Journal of Physics: Conference Series, 2011, vol. 305, no. 1, p. 012061: IOP Publishing.

[10] R. Hojjati-Talemi, A. Zahedi, and P. D. Baets, "Fretting fatigue failure mechanism of automotive shock absorber valve," International Journal of Fatigue, vol. 73, pp. 58-65, 2015/04/01/ 2015.

[11] C. Jiménez-Peña, R. H. Talemi, B. Rossi, and D. Debruyne, "Investigations on the fretting fatigue failure mechanism of bolted joints in high strength steel subjected to different levels of pretension," Tribology International, vol. 108, pp. 128-140, 2017/04/01/ 2017.

[12] T. Rauert, J. Herrmann, P. Dalhoff, and M. Sander, "Fretting fatigue induced surface cracks under shrink fitted main bearings in wind turbine rotor shafts," Procedia Structural Integrity, vol. 2, pp. 3601-3609, 2016/01/01/ 2016.

[13] S. Sheng, J. Flegler, B. J. Becs, and M. Dankert, "HCF component tests on full-scale low pressure steam turbine end stage blades," in ASME Turbo Expo 2016: Turbomachinery Technical Conference and Exposition, 2016, pp. V008T26A022-V008T26A022: American Society of Mechanical Engineers.

[14]D. A. Hills, "Mechanics of fretting fatigue," Wear, vol. 175, no. 1-2, pp. 107-113, 1994.

[15] S. Romano, A. Brandão, J. Gumpinger, M. Gschweitl, and S. Beretta, "Qualification of AM parts: Extreme value statistics applied to tomographic measurements," Materials \& Design, vol. 131, pp. 32-48, 2017/10/05/ 2017.

[16] A. Yadollahi and N. Shamsaei, "Additive manufacturing of fatigue resistant materials: Challenges and opportunities," International Journal of Fatigue, vol. 98, pp. 14-31, 2017/05/01/ 2017.

[17] G. H. Majzoobi, R. Hojjati, and M. Soori, "Fretting fatigue behavior of Al7075-T6 at sub-zero temperature," Tribology International, vol. 44, no. 11, pp. 1443-1451, 2011/10/01/2011. 
[18] J. De Pauw, W. De Waele, R. Hojjati-Talemi, and P. De Baets, "On the use of digital image correlation for slip measurement during coupon scale fretting fatigue experiments," International Journal of Solids and Structures, vol. 51, no. 18, pp. 3058-3066, 2014/09/01/ 2014.

[19] R. H. Talemi, "Numerical measures of non-proportionality degree in incomplete contact subjected to fretting fatigue loading," Theoretical and Applied Fracture Mechanics, vol. 90, pp. 3342, 2017/08/01/ 2017.

[20] N. Shamsaei, A. Yadollahi, L. Bian, and S. M. Thompson, "An overview of Direct Laser Deposition for additive manufacturing; Part II: Mechanical behavior, process parameter optimization and control," Additive Manufacturing, vol. 8, pp. 12-35, 2015. [21] N. T. Aboulkhair, N. M. Everitt, I. Ashcroft, and C. Tuck, "Reducing porosity in AlSi10Mg parts processed by selective laser melting," Additive Manufacturing, vol. 1, pp. 77-86, 2014. [22] N. B. Dahotre and S. Harimkar, Laser fabrication and machining of materials. Springer Science \& Business Media, 2008.

[23] S. Beretta and S. Romano, "A comparison of fatigue strength sensitivity to defects for materials manufactured by AM or traditional processes," International Journal of Fatigue, vol. 94, pp. 178-191, 2017.

[24] S. Romano, A. Brückner-Foit, A. Brandão, J. Gumpinger, T. Ghidini, and S. Beretta, "Fatigue properties of AlSi10Mg obtained by additive manufacturing: Defect-based modelling and prediction of fatigue strength," Engineering Fracture Mechanics, vol. 187, pp. 165-189, 2018/01/01/ 2018.

[25] T. M. Mower and M. J. Long, "Mechanical behavior of additive manufactured, powder-bed laser-fused materials," Materials Science and Engineering: A, vol. 651, pp. 198-213, 2016/01/10/ 2016.

[26] L. Kachanov, "Time of the rupture process under creep conditions, Izy Akad," Nank SSR Otd Tech Nauk, vol. 8, pp. 26-31, 1958.

[27] J. Chaboche and P. Lesne, "A non- linear continuous fatigue damage model," Fatigue \& fracture of engineering materials \& structures, vol. 11, no. 1, pp. 1-17, 1988.

[28] J. Lemaitre, A course on damage mechanics. Springer Science \& Business Media, 2012. [29] V. V. Bolotin, Mechanics of fatigue. Crc Press, 1999. 
[30] B. Jalalahmadi, F. Sadeghi, and D. Peroulis, "A numerical fatigue damage model for life scatter of MEMS devices," Journal of Microelectromechanical Systems, vol. 18, no. 5, pp. 10161031, 2009.

[31] R. Hojjati Talemi, "Numerical modelling techniques for fretting fatigue crack initiation and propagation," 2014.

[32] R. Hojjati-Talemi and M. A. Wahab, "Fretting fatigue crack initiation lifetime predictor tool: Using damage mechanics approach," Tribology International, vol. 60, pp. 176-186, 2013.

[33] R. Hojjati-Talemi, M. A. Wahab, J. De Pauw, and P. De Baets, "Prediction of fretting fatigue crack initiation and propagation lifetime for cylindrical contact configuration," Tribology International, vol. 76, pp. 73-91, 2014.

[34] R. Hojjati-Talemi, M. A. Wahab, E. Giner, and M. Sabsabi, "Numerical estimation of fretting fatigue lifetime using damage and fracture mechanics," Tribology Letters, vol. 52, no. 1, pp. 11-25, 2013. 


\section{FIGURE 1}

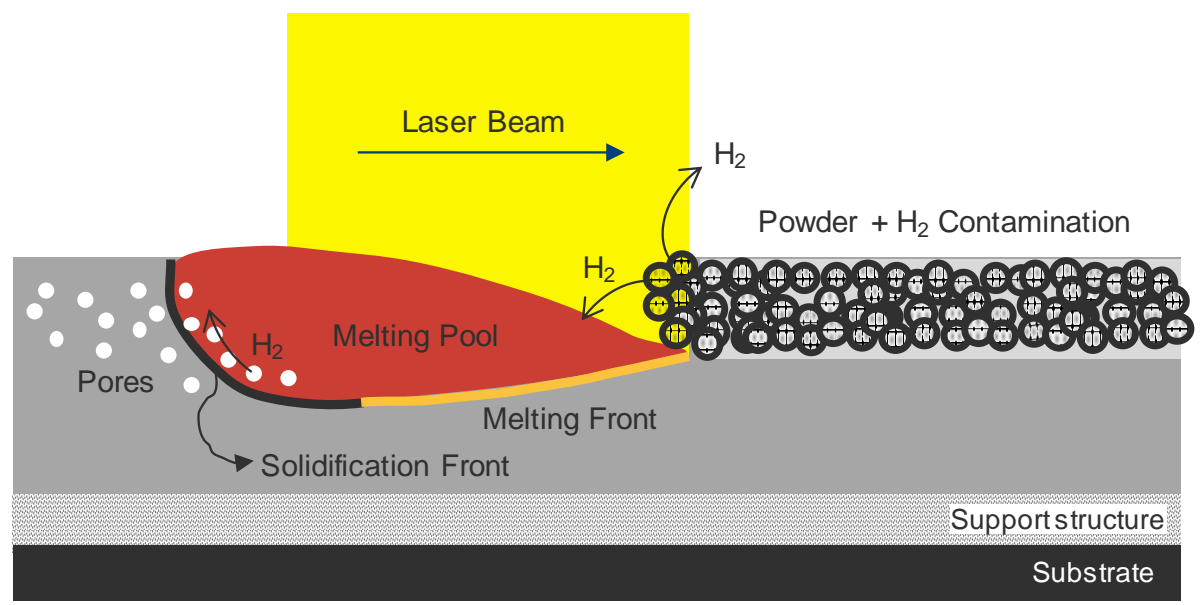

(a)

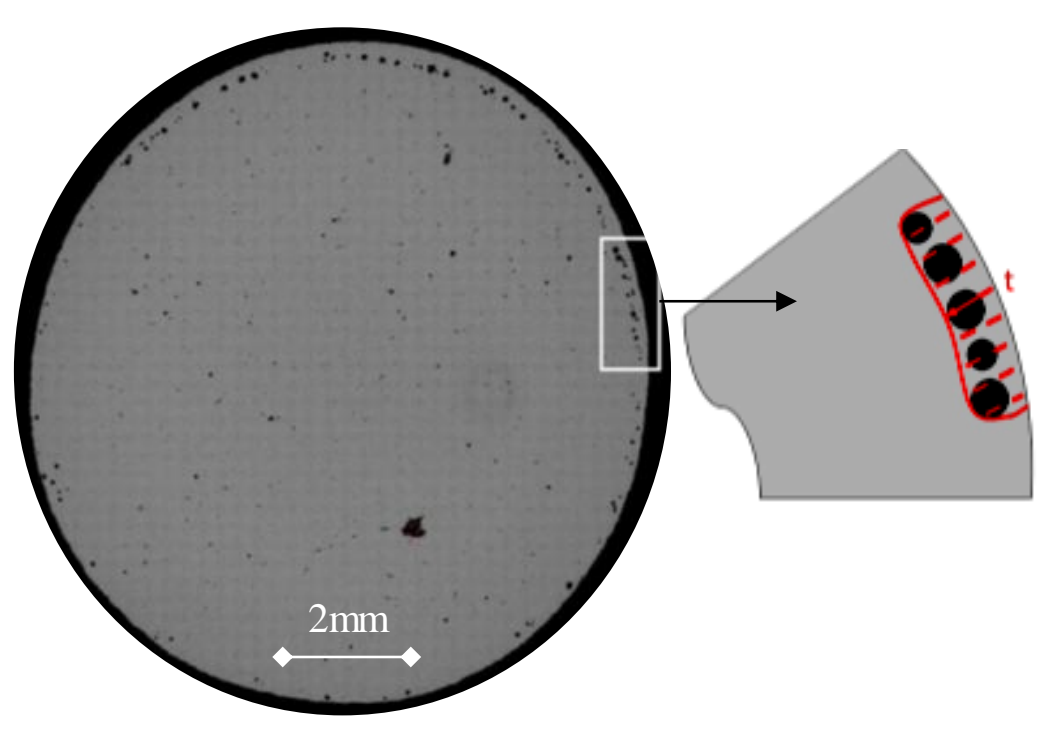

(b) 
$\sigma_{\mathrm{a}}[\mathrm{MPa}]$

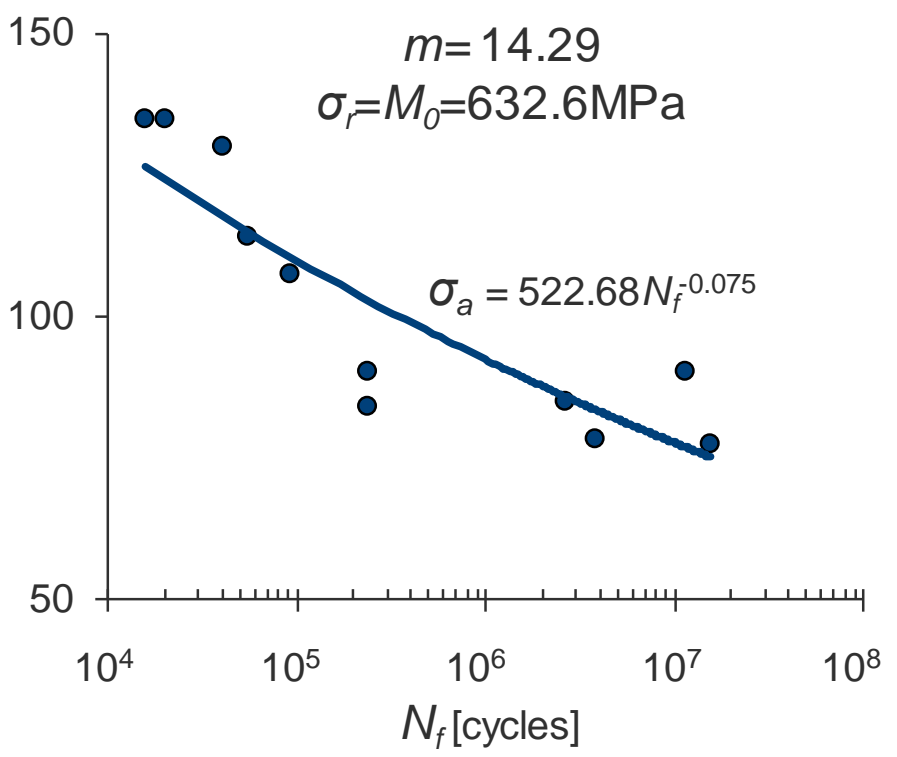


FIGURE 3

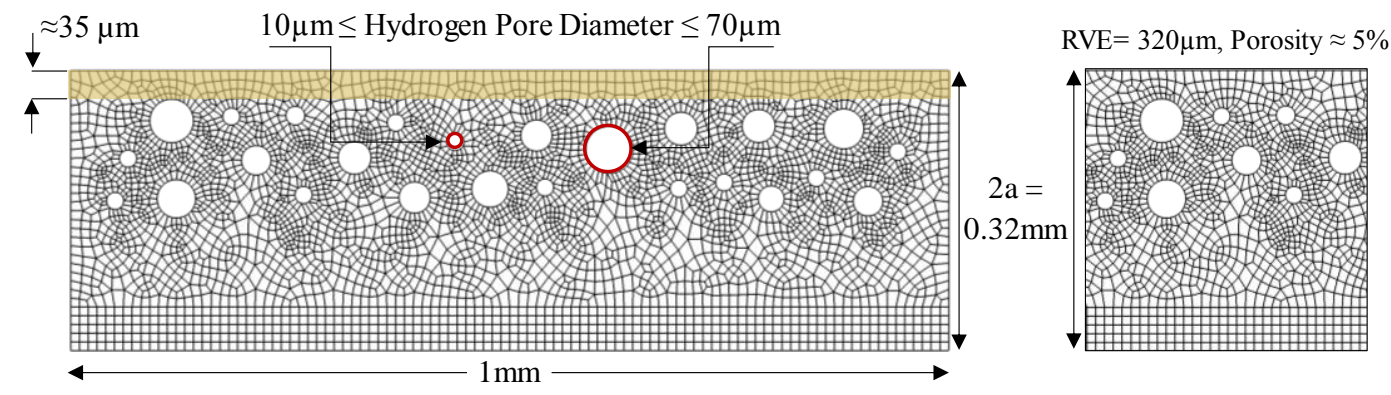


FIGURE 4

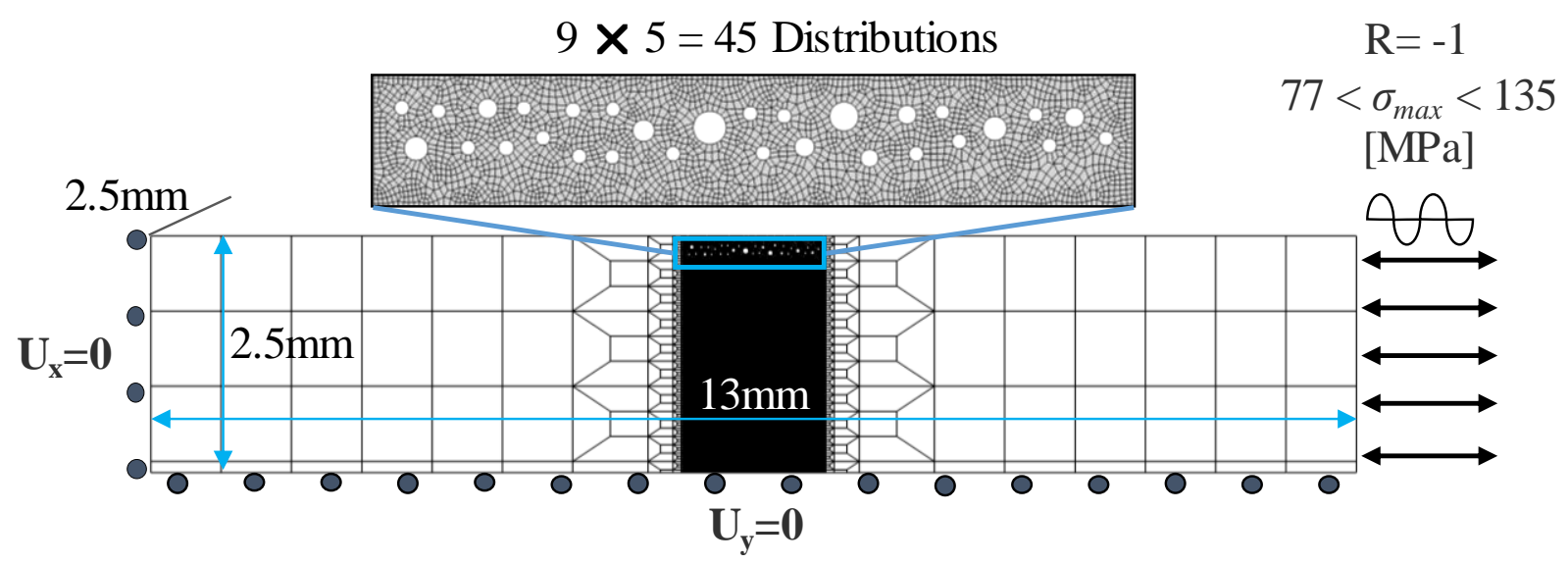

(a)

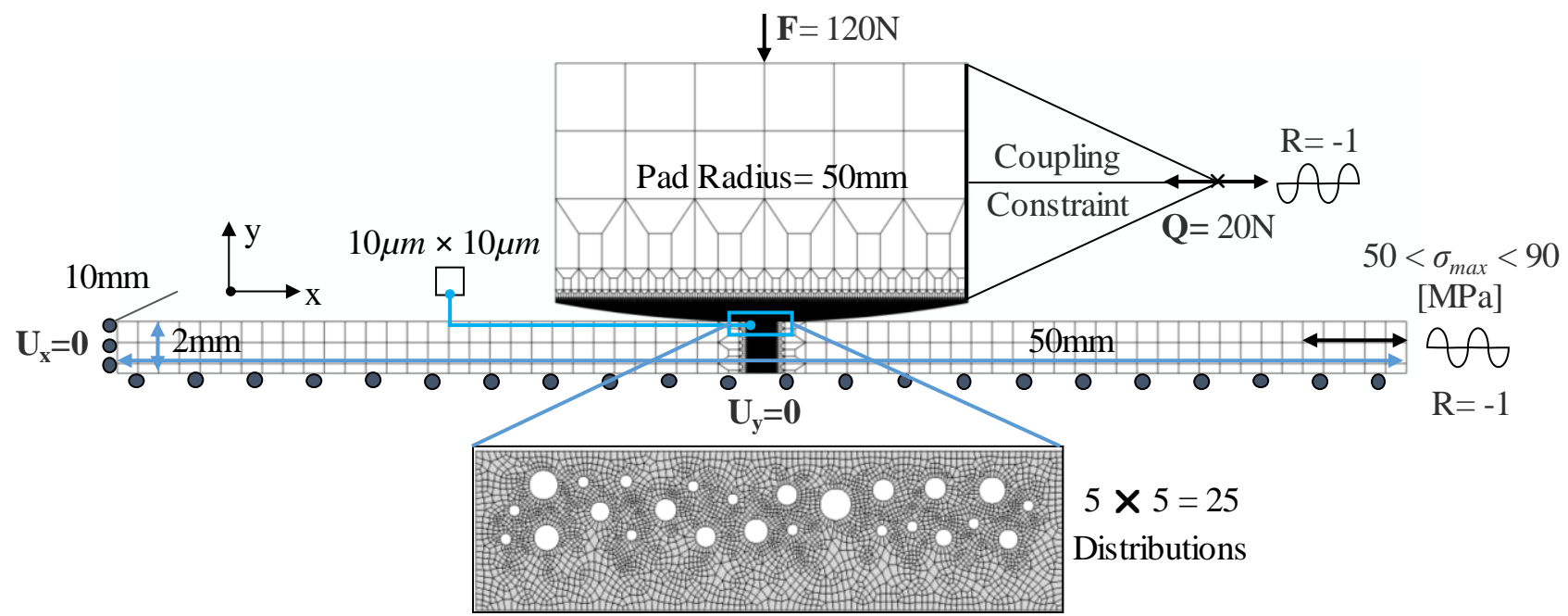

(b) 
FIGURE 5

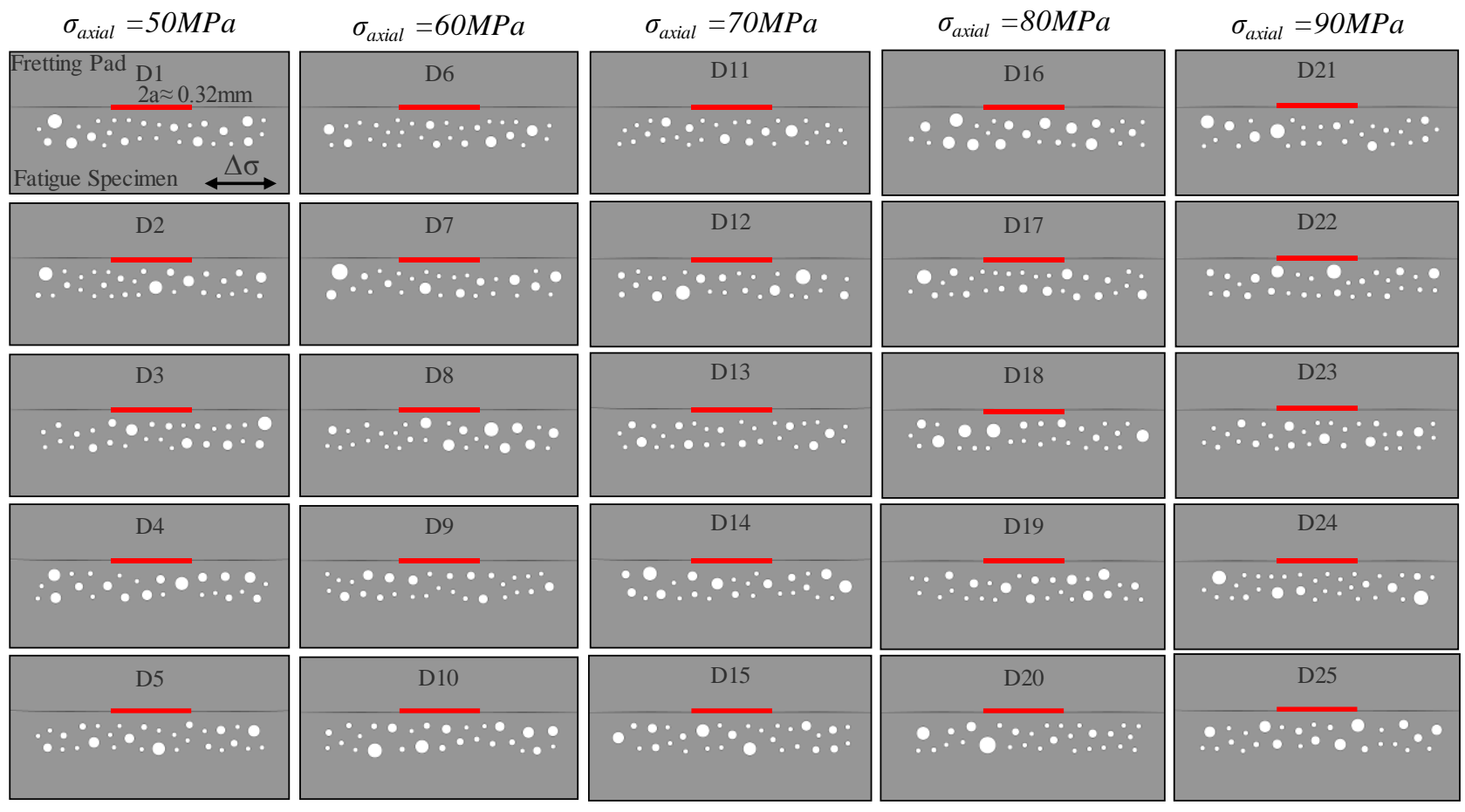

28

29

30

31

32

33

34

35

36

37

38

39

40

41

42

43

44

45

46

47

48

49

50

51

52

53

54

55

56

57

58

59

60

61

62 


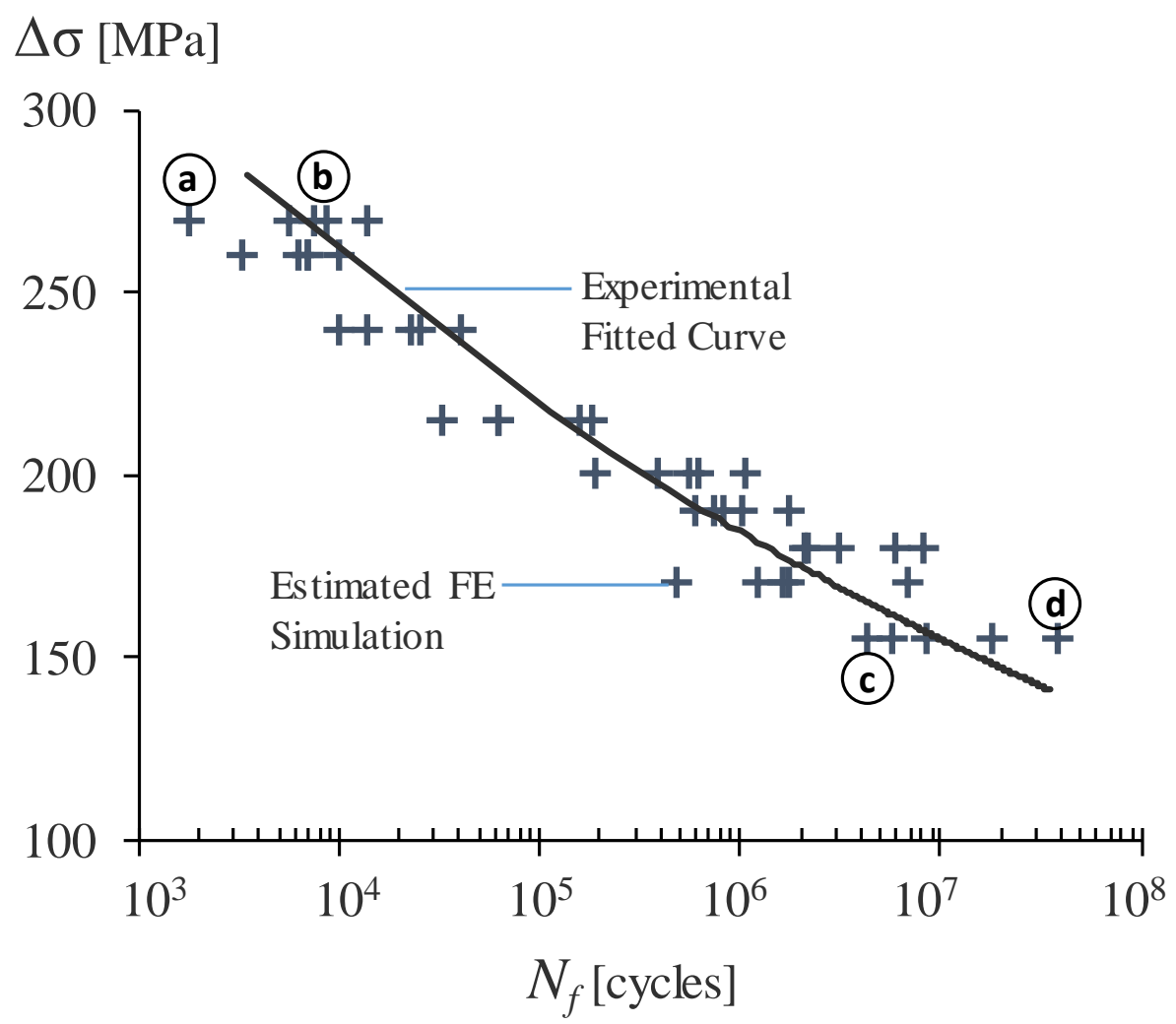




\section{FIGURE 7}

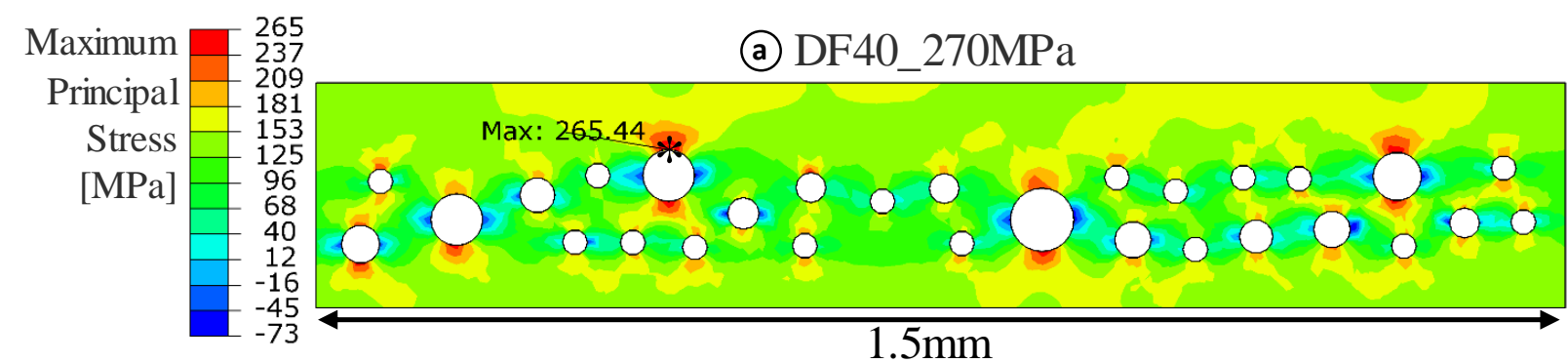

(b) DF45-270MPa

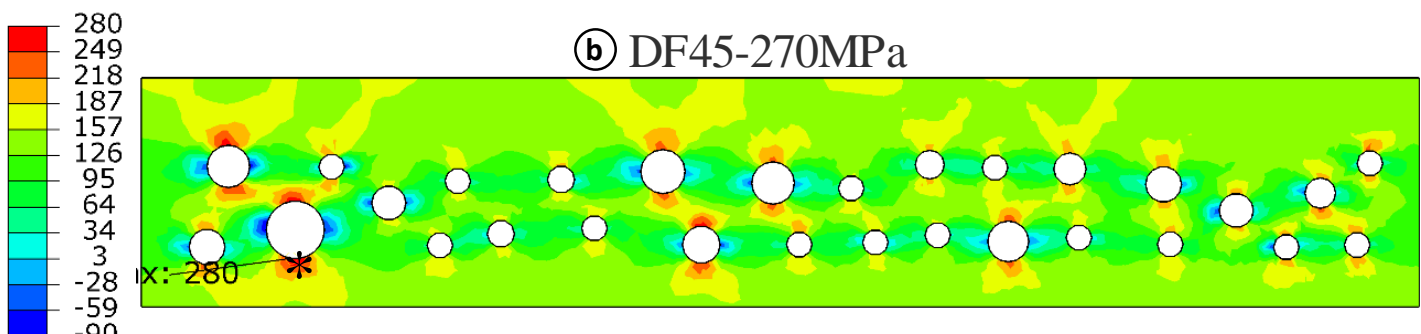

(c) $\mathrm{DF} 1-155 \mathrm{MPa}$
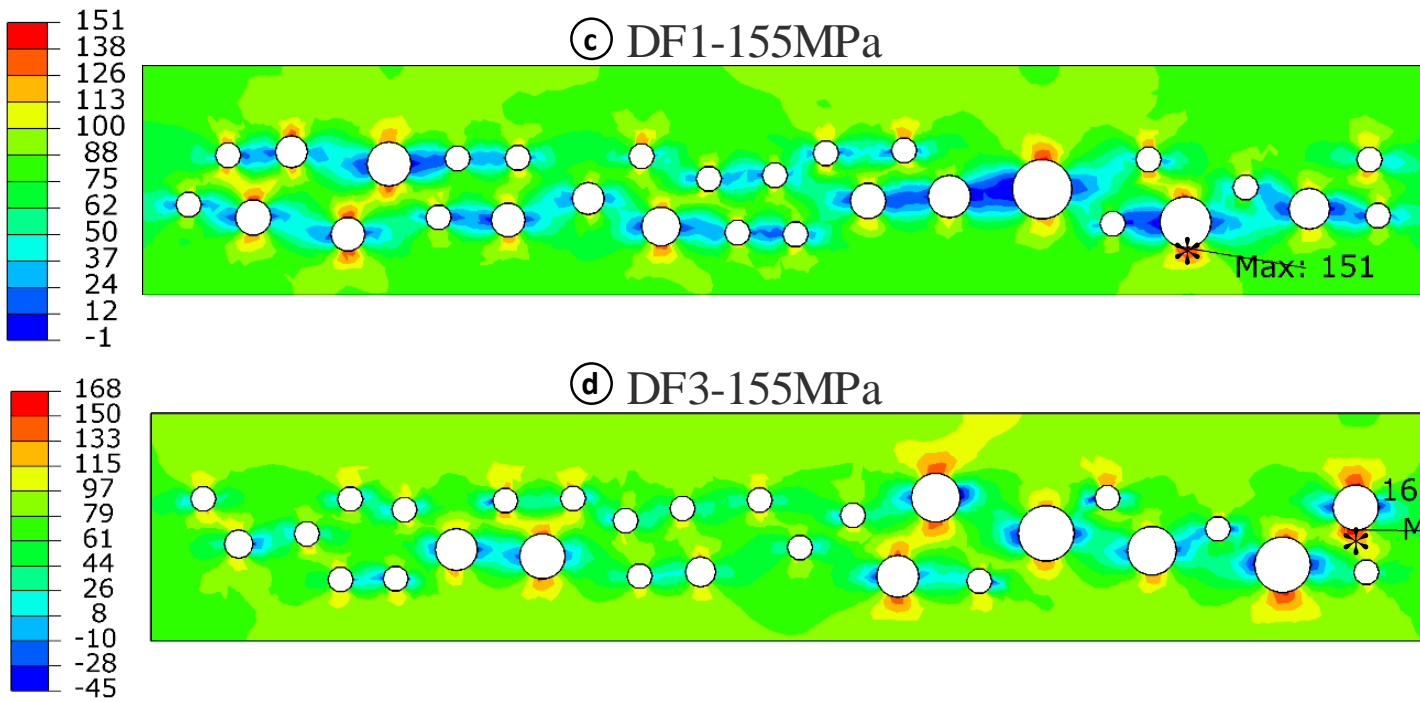

(d) $\mathrm{DF} 3-155 \mathrm{MPa}$

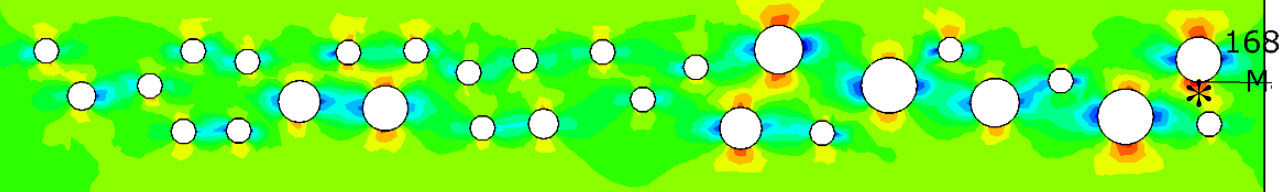




\section{FIGURE 8}
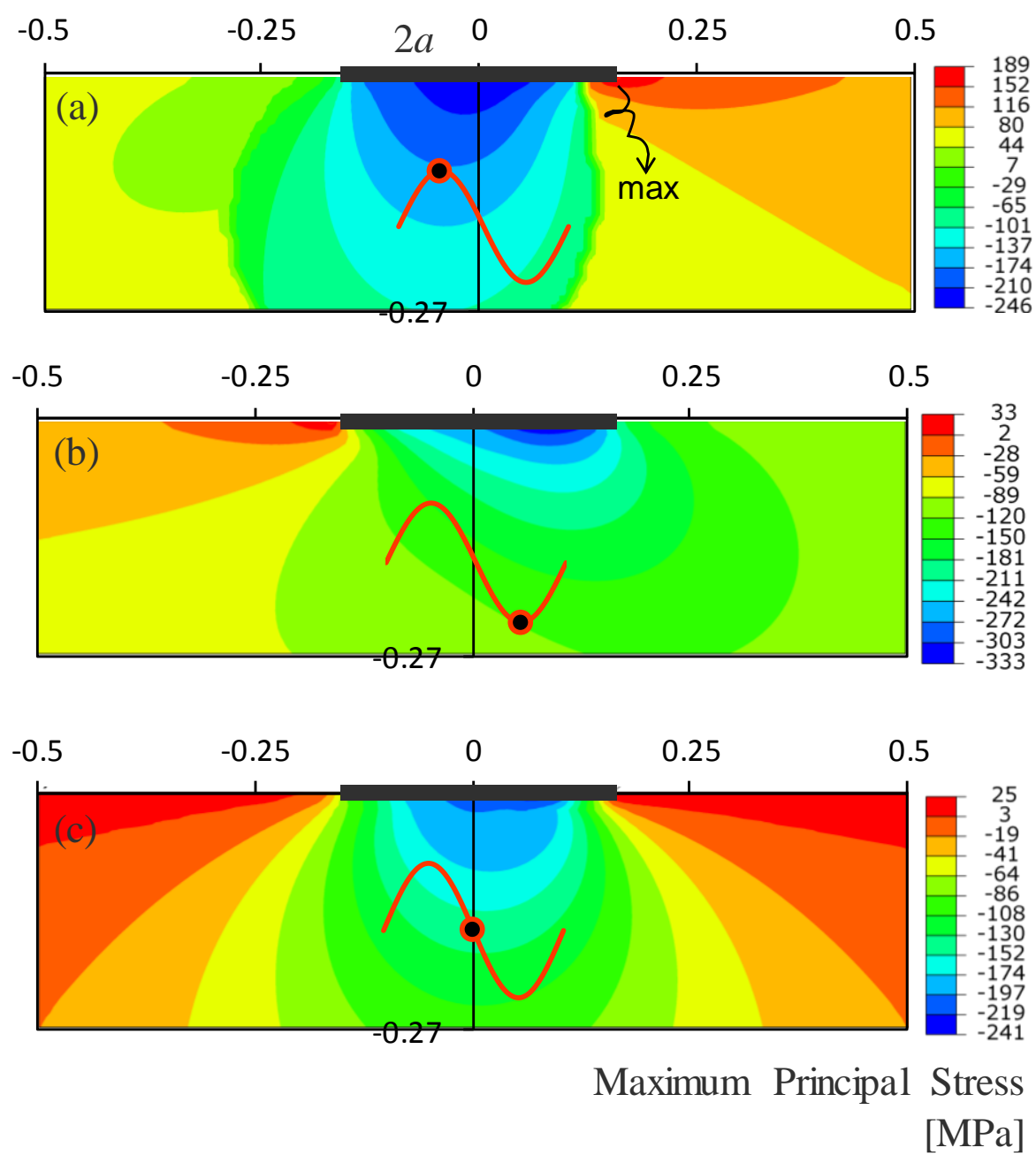
FIGURE 9
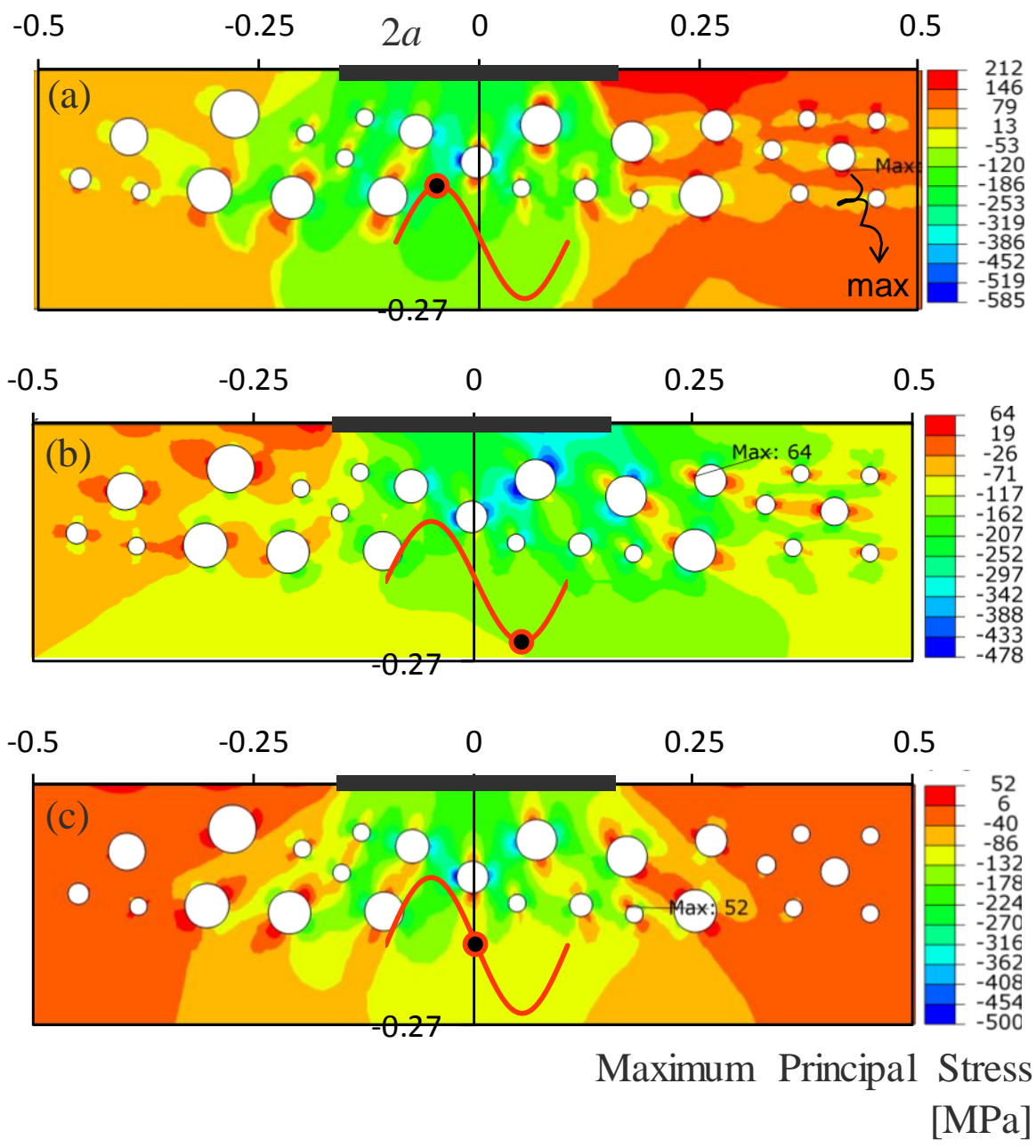
FIGURE 10
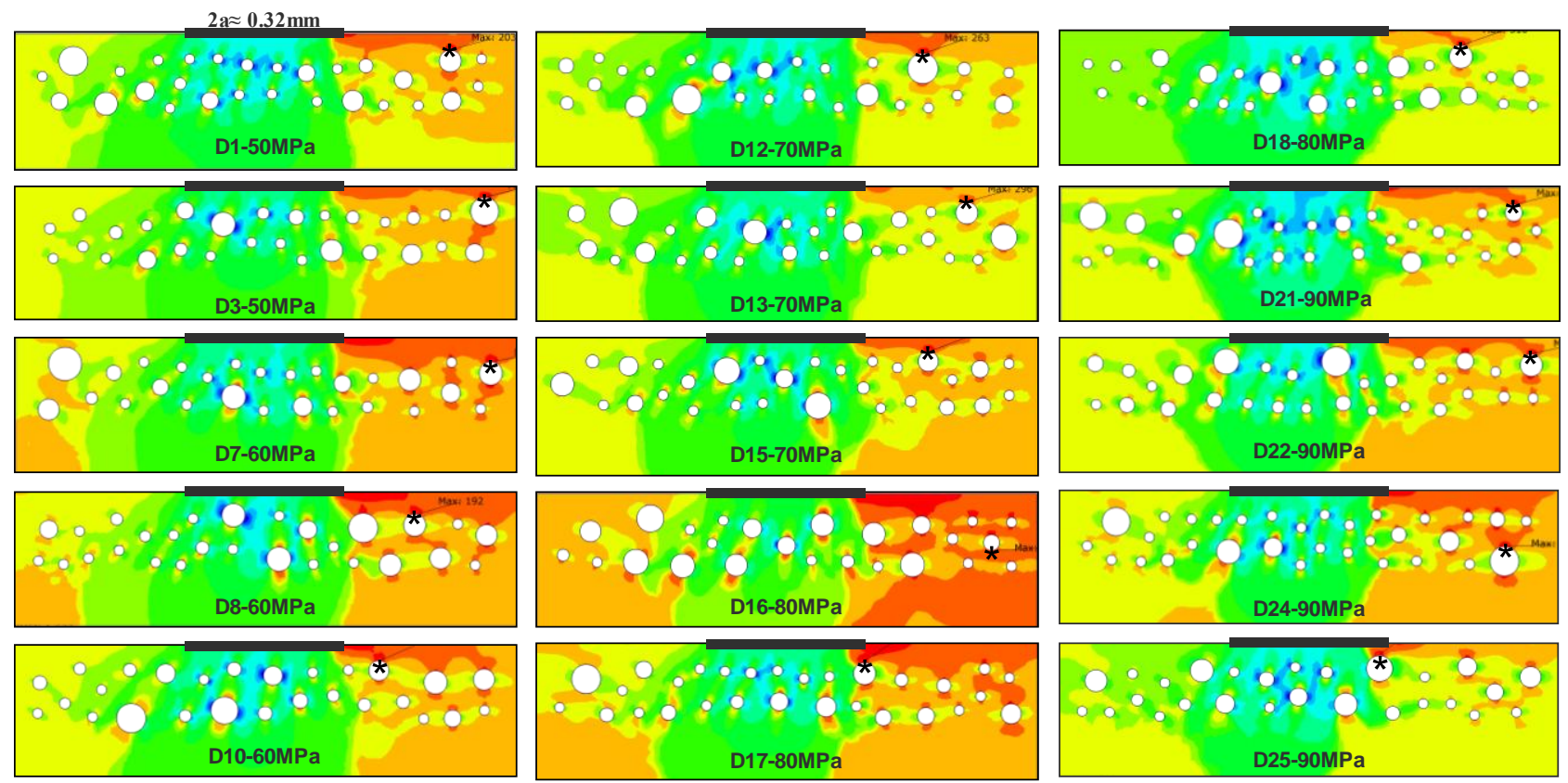
1

2

3

4

5

6

7

8

9

10

11

12

13

14

15

16

17

18

19

20

21

22

23

24

25

26

27

28

29

30

31

32

33

34

35

36

37

38

39

40

41

42

43

44

45

46

47

48

49

50

51

52

53

54

55

56

57

58

59

60

61

62

63

64

65

\section{FIGURE 11}
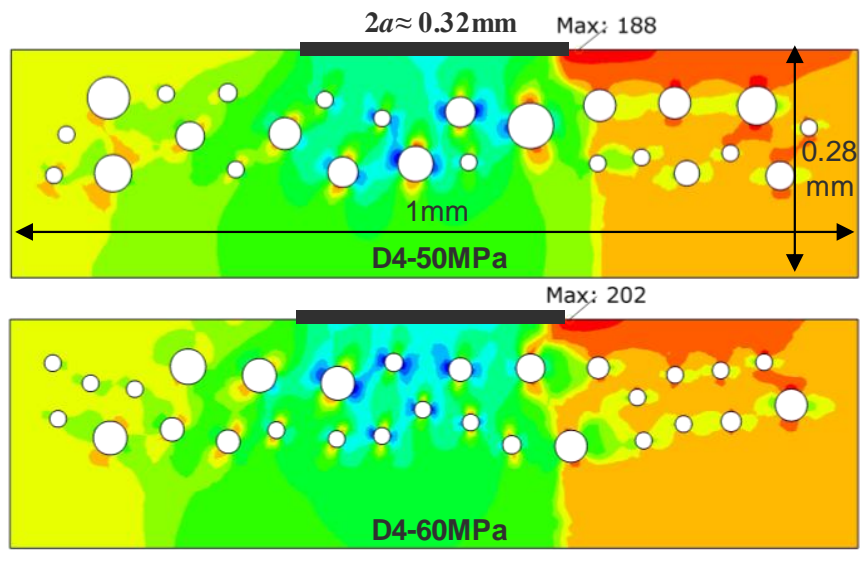

Max: 197
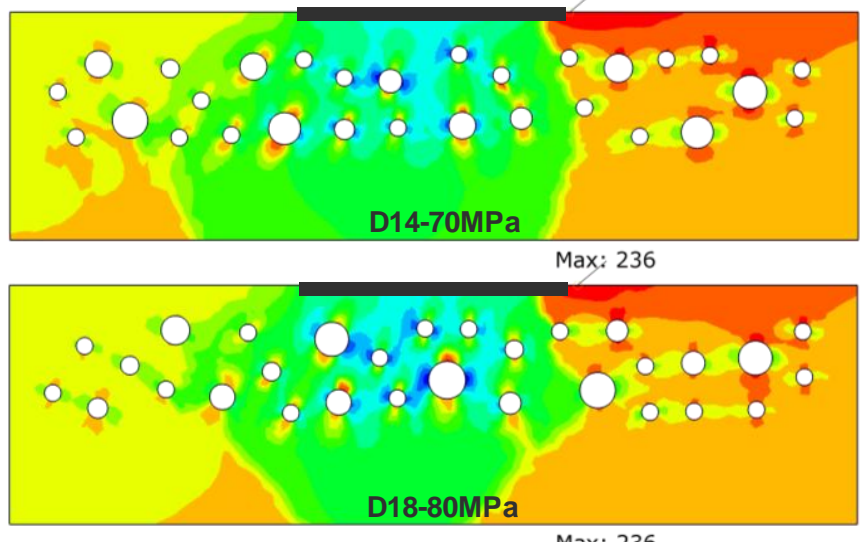

Max: 236

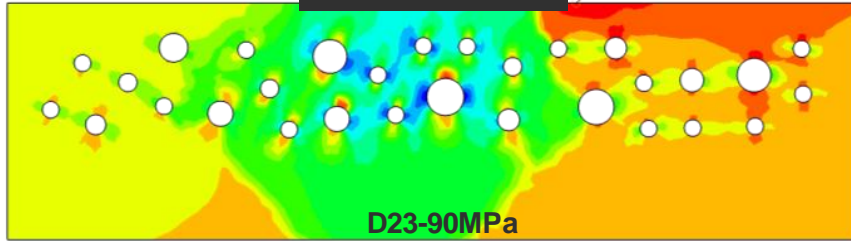

D23-90MPa 
FIGURE 12

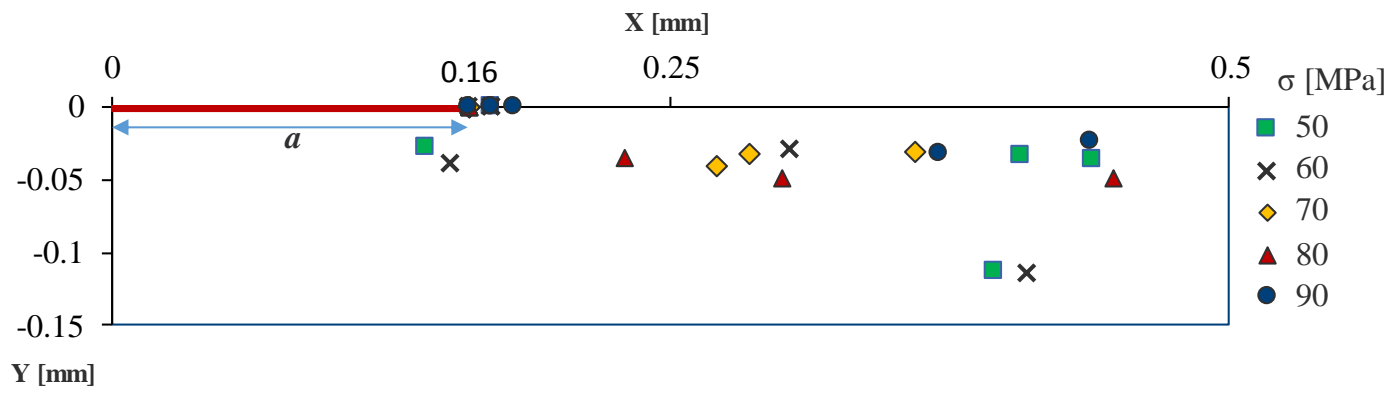

(a)

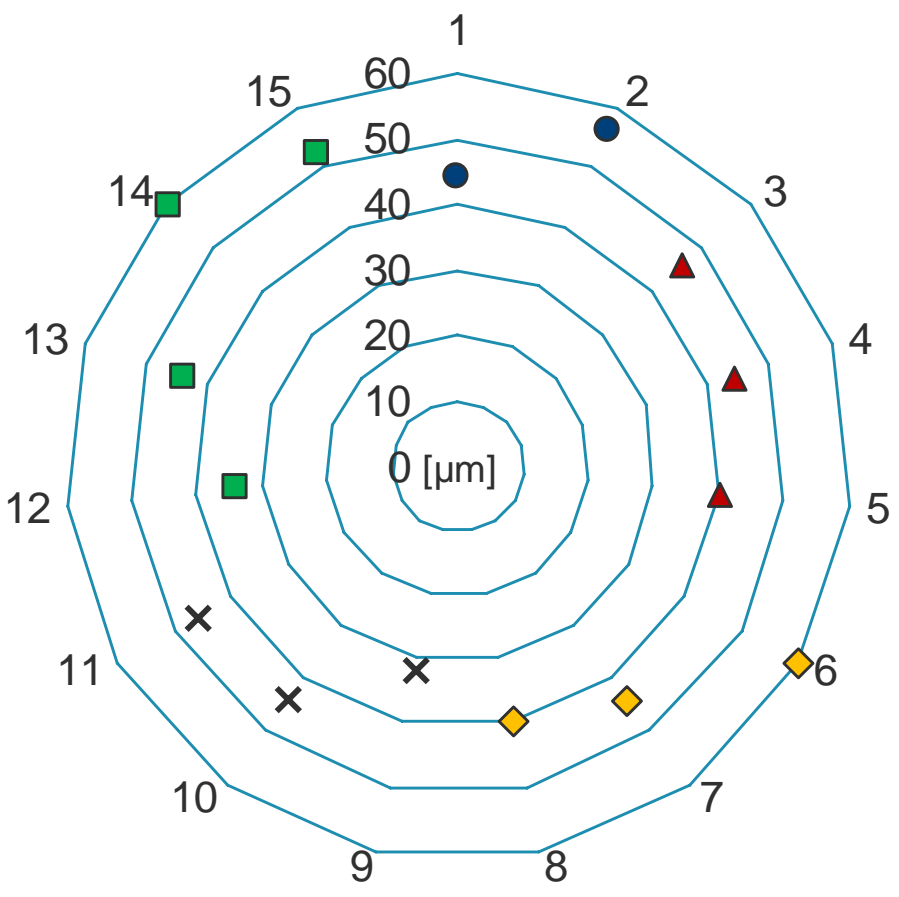

Killer Defect Size

18

19

20

21

22

23

24

25

26

27

28

29

30

31

32

33

34

35

36

37

38

39

40

41

42

43

44

45

46

47

48

49

50

51

52

53

54

55

56

57

58

59

60

Killer Defect Size

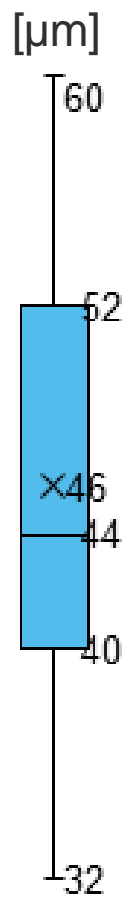

(b) 


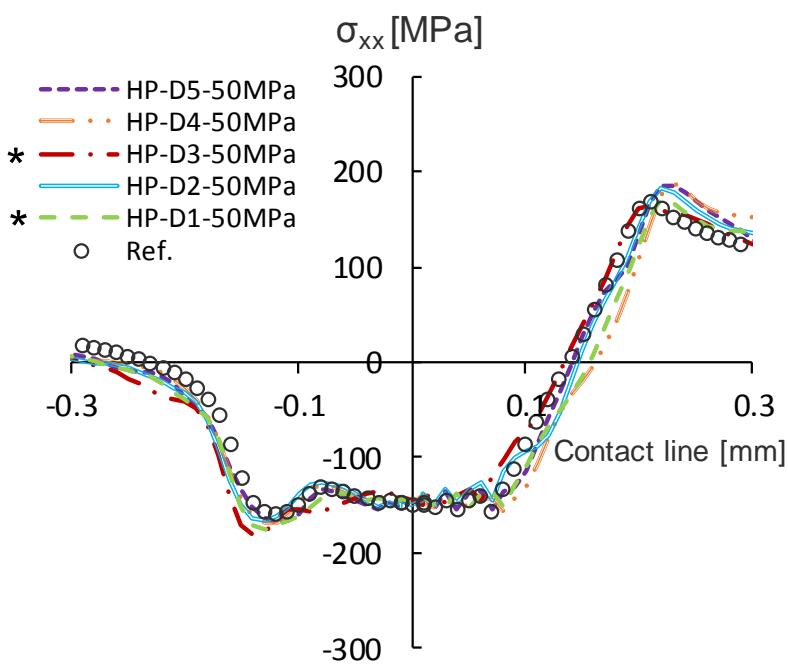

(a)

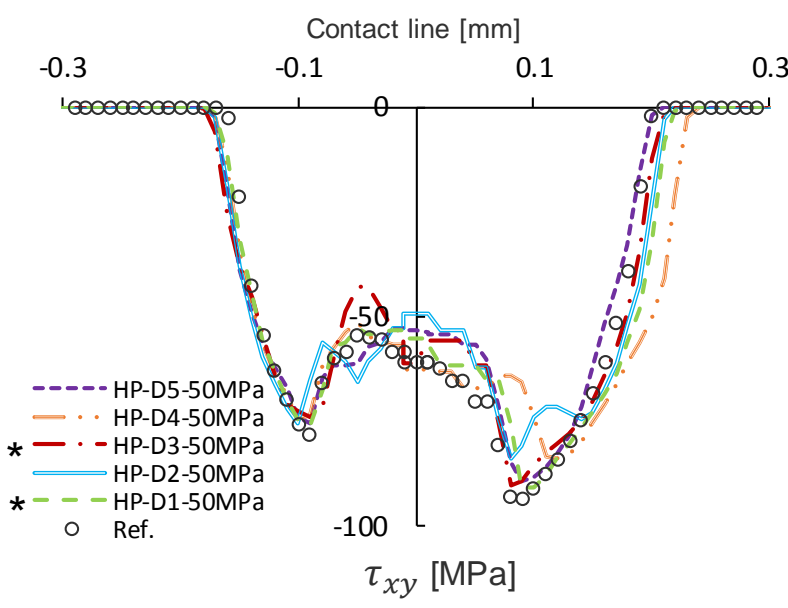

(b)

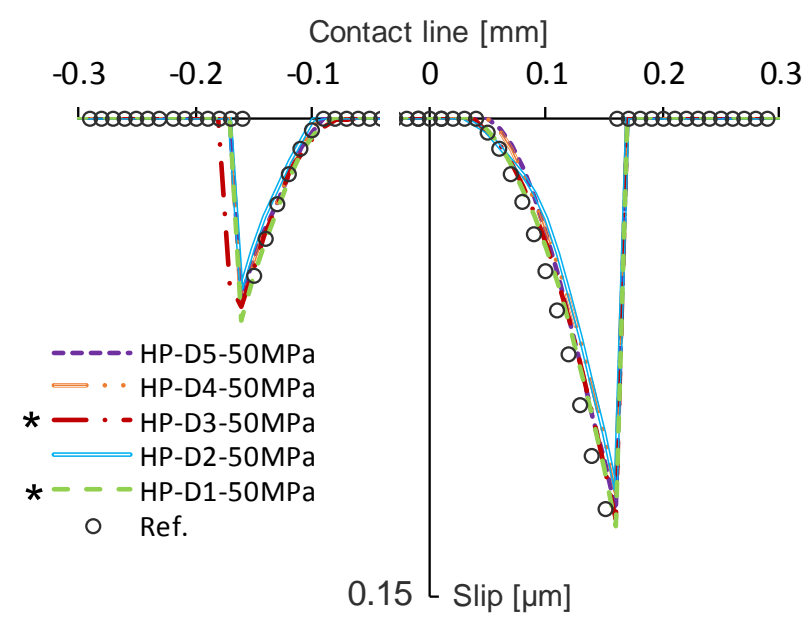

(c) 
1

2

3

4

7

8

10

11

12

13

14

15

16

17

18

19

20

21

22

23

24

25

26

27

28

29

30

31

32

33

34

35

36

37

38

39

40

41

42

43

44

45

46

47

48

49

50

51

52

53

54

55

56

57

58

59

60

61

62

63

64

65 


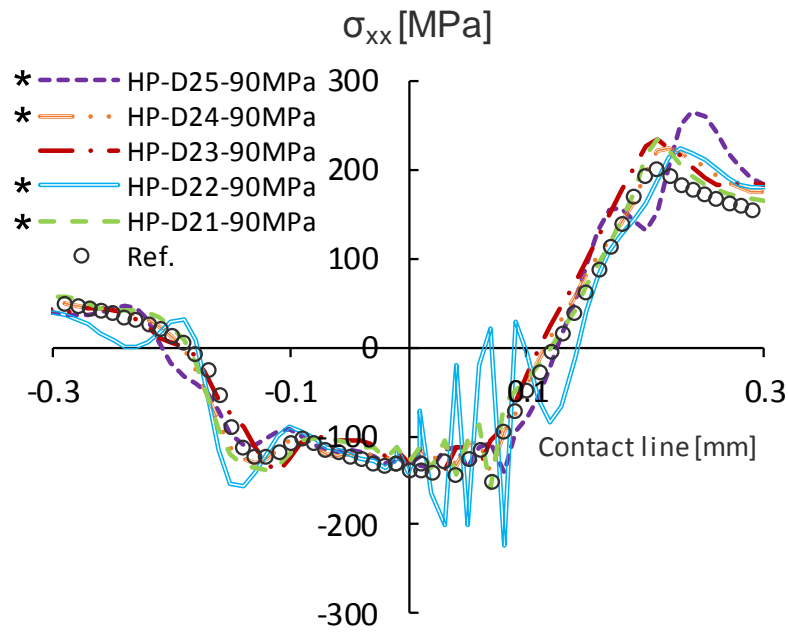

(a)

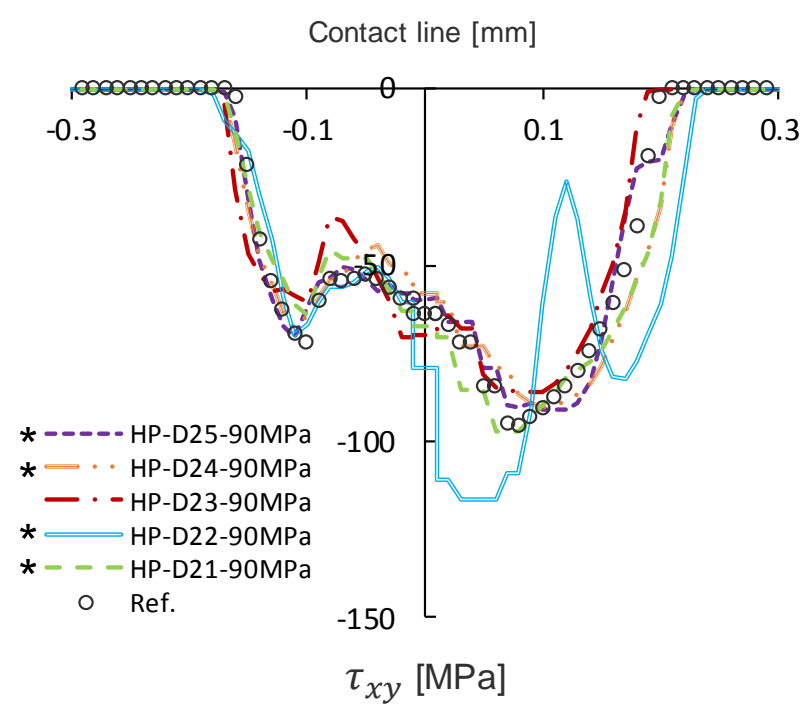

(b)

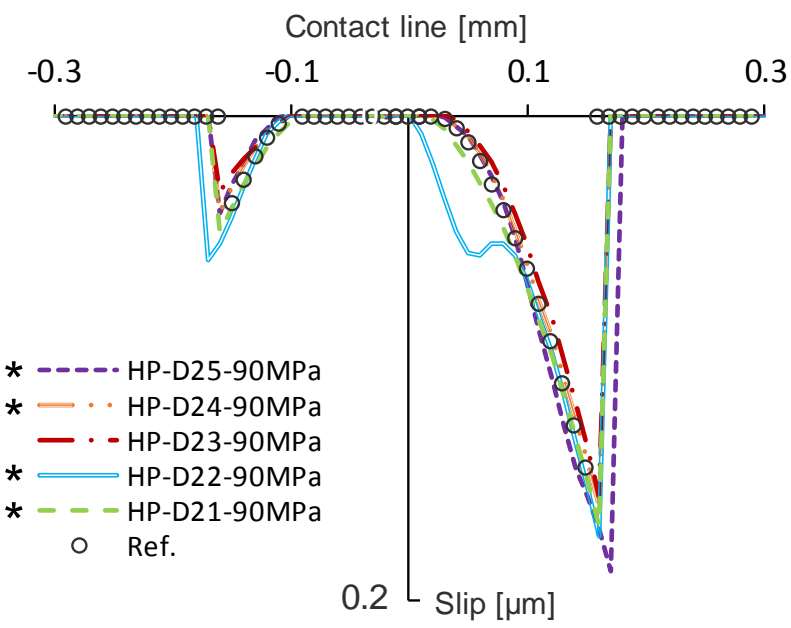

(c) 


\section{FIGURE 15}

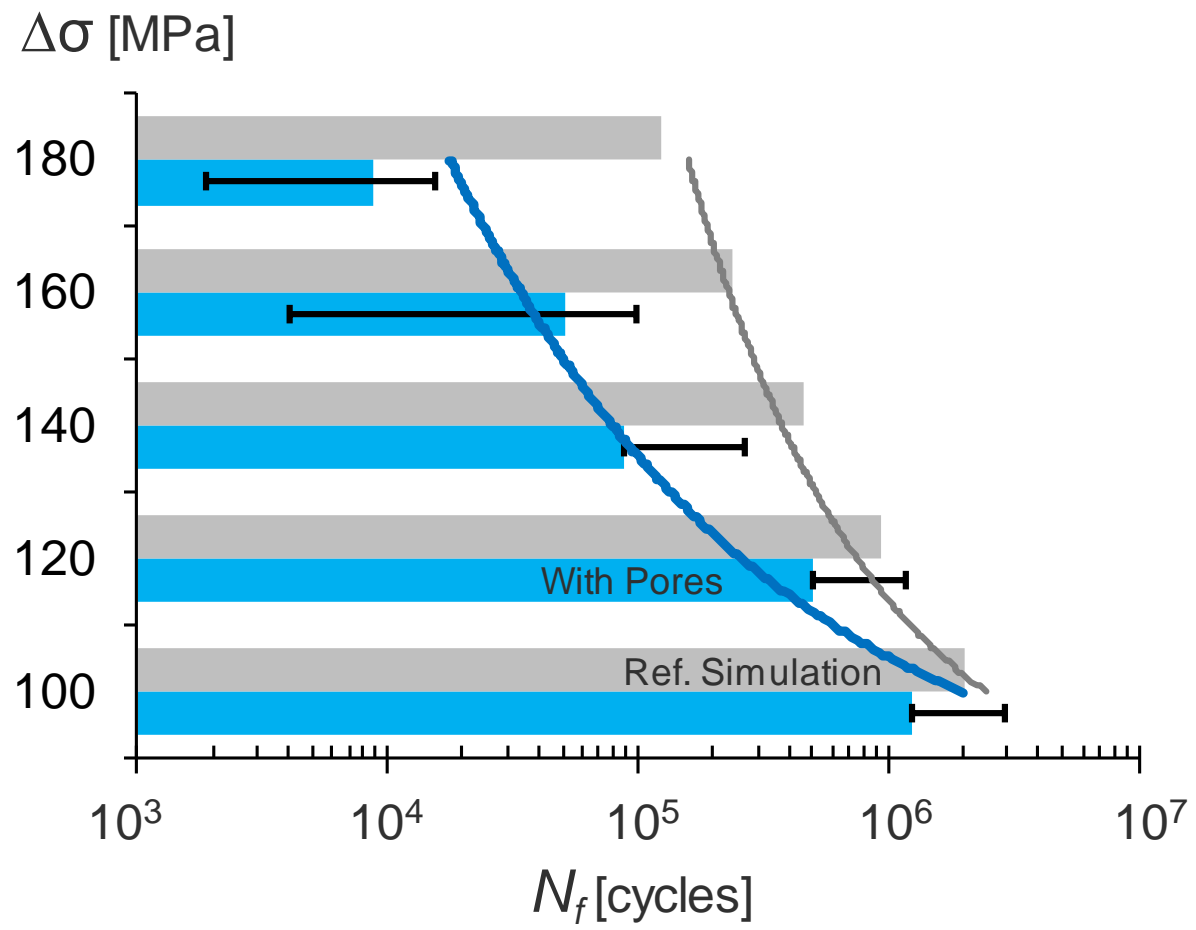

$\Delta \sigma[\mathrm{MPa}]$ 

$\approx 35 \mu \mathrm{m} \quad 10 \mu \mathrm{m} \leq$ Hydrogen Pore Diameter $\leq 70 \mu \mathrm{m}$

$\mathrm{RVE}=320 \mu \mathrm{m}$, Porosity $\approx 5 \%$ $(1)$ $2 \mathrm{a}=$

$0.32 \mathrm{~mm}$ $1 \mathrm{~mm}$

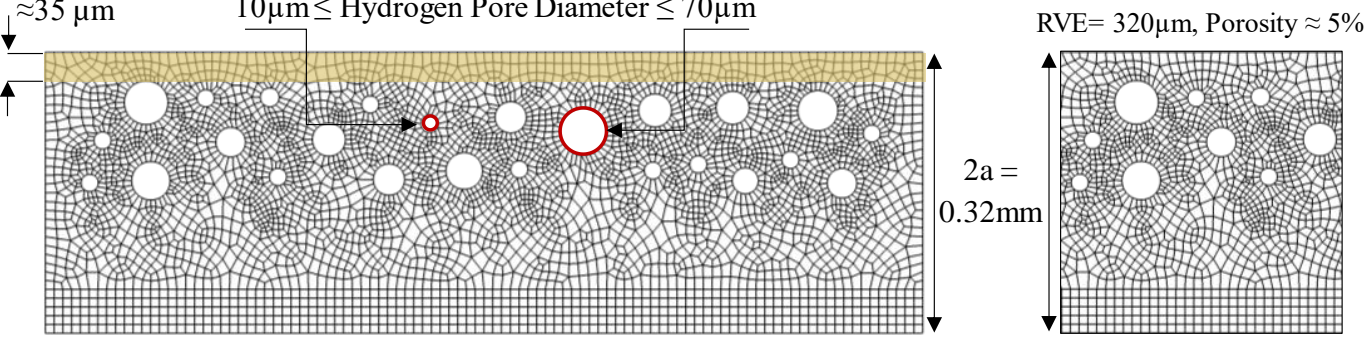


$9 \times 5=45$ Distributions

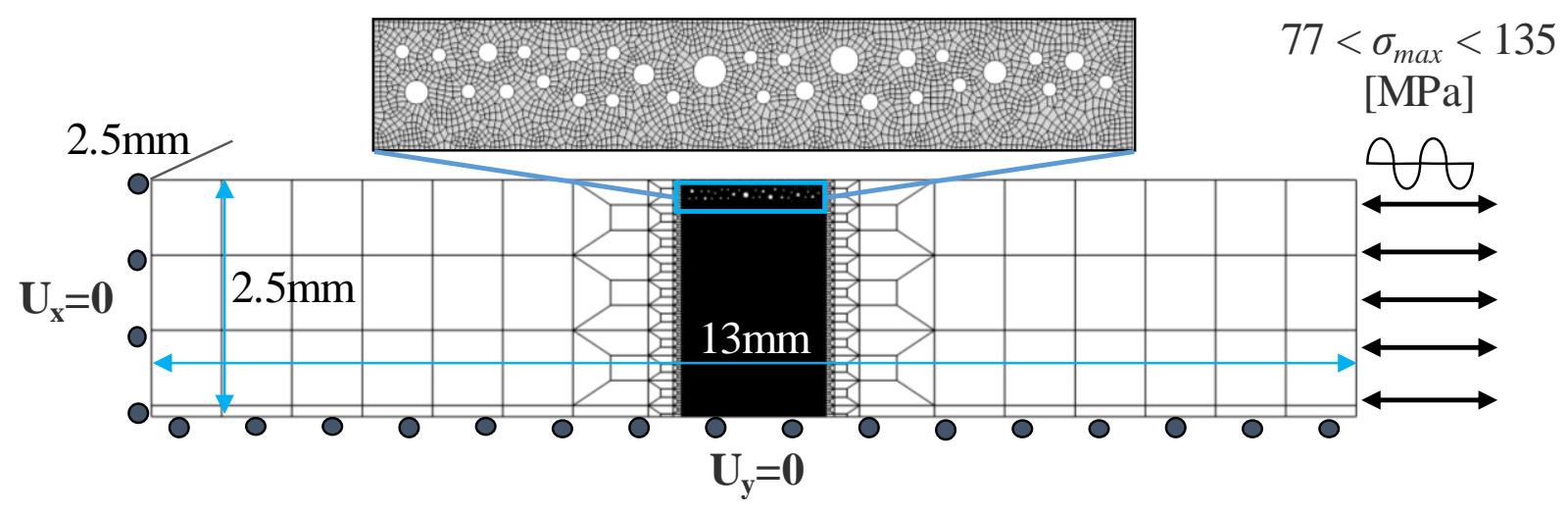

(a)

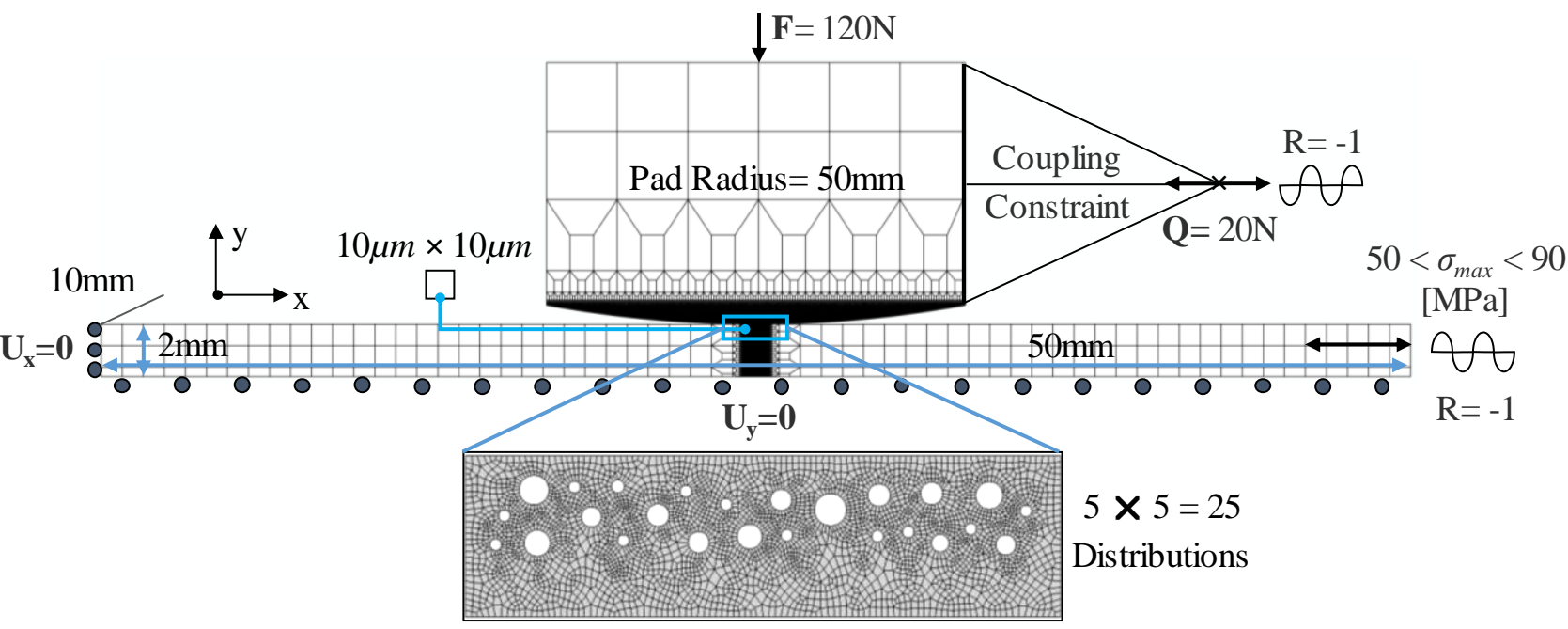

(b) 
$\sigma_{\text {axial }}=50 \mathrm{MPa}$

Fretting Pad D1

$\because \because \because 2 \mathrm{a} \approx 0.32 \mathrm{~mm}$

Fatigue Specimen

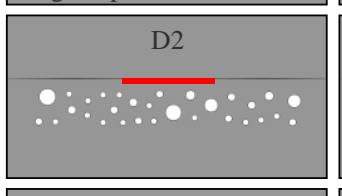

D3

$\because \ldots \because \cdots \cdots$

$\therefore \cdots$

D4

$\therefore \because \because \because 0 \div \because \cdots$

D5

$\because \because \because \because \because \because \because \because \%$ $\sigma_{\text {axial }}=60 \mathrm{MPa}$

$\sigma_{\text {axial }}=70 \mathrm{MPa}$

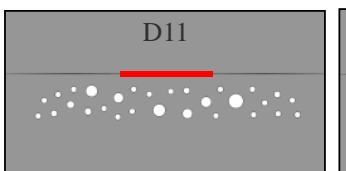

$80 \mathrm{MPa}$

$\sigma_{\text {axial }}=90 M P a$

\section{D21}

$\because \because \because \because \because \because \because \%$

\section{D7}

$0 \because \because \because \because \because: \div$

$\because \because 0 \div \because \div \quad:$

\section{D8}

$\therefore \therefore \therefore \therefore \div \div$

\section{D9}

$\because \because 0 \circ \cdots \circ \cdot \cdots$

$\therefore \because \cdots \because \because \because 0 \%$

$\overbrace{}^{1}$

$\because 0$ ०.0.0.0.…

\section{D12}

$\because \therefore \because \because \because \cdots \therefore \because$

$\therefore \therefore \because \therefore \therefore \cdots$

$\because \therefore 0 \therefore \therefore \therefore \circ$

$\because 0: \because 0: \because \cdots \circ$

$\because \because \because \because \because \because \cdots \cdots$

\section{D15}

$\because \because 0 \because \because \because \because$

D22

$\because \cdots \cdots, \cdots \because \cdots$

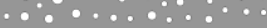

D23

$\therefore \because \because \because \because \because \cdots: \vdots$

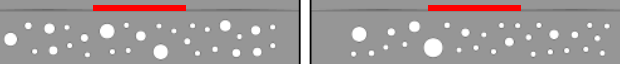

D24

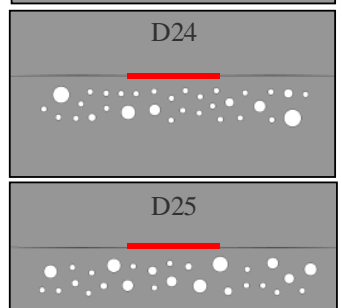


$\Delta \sigma[\mathrm{MPa}]$

300

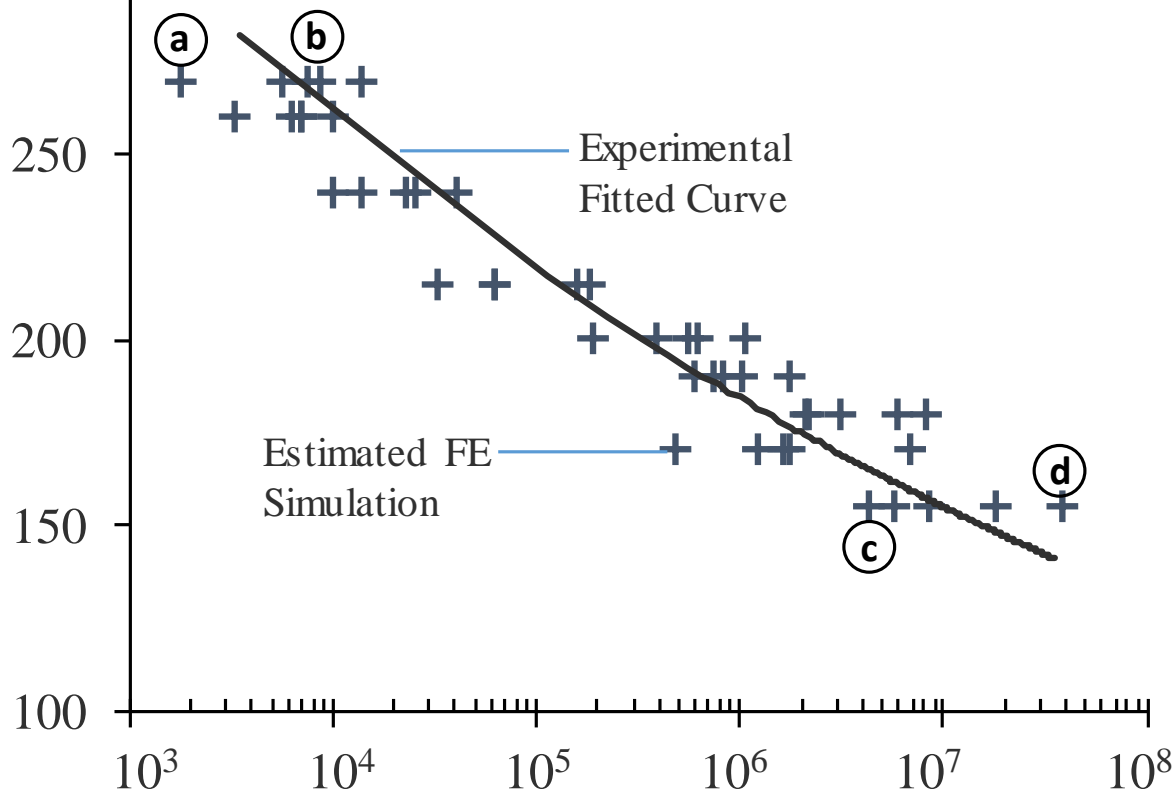

$N_{f}$ [cycles] 
Maximum

Principal Stress [MPa]
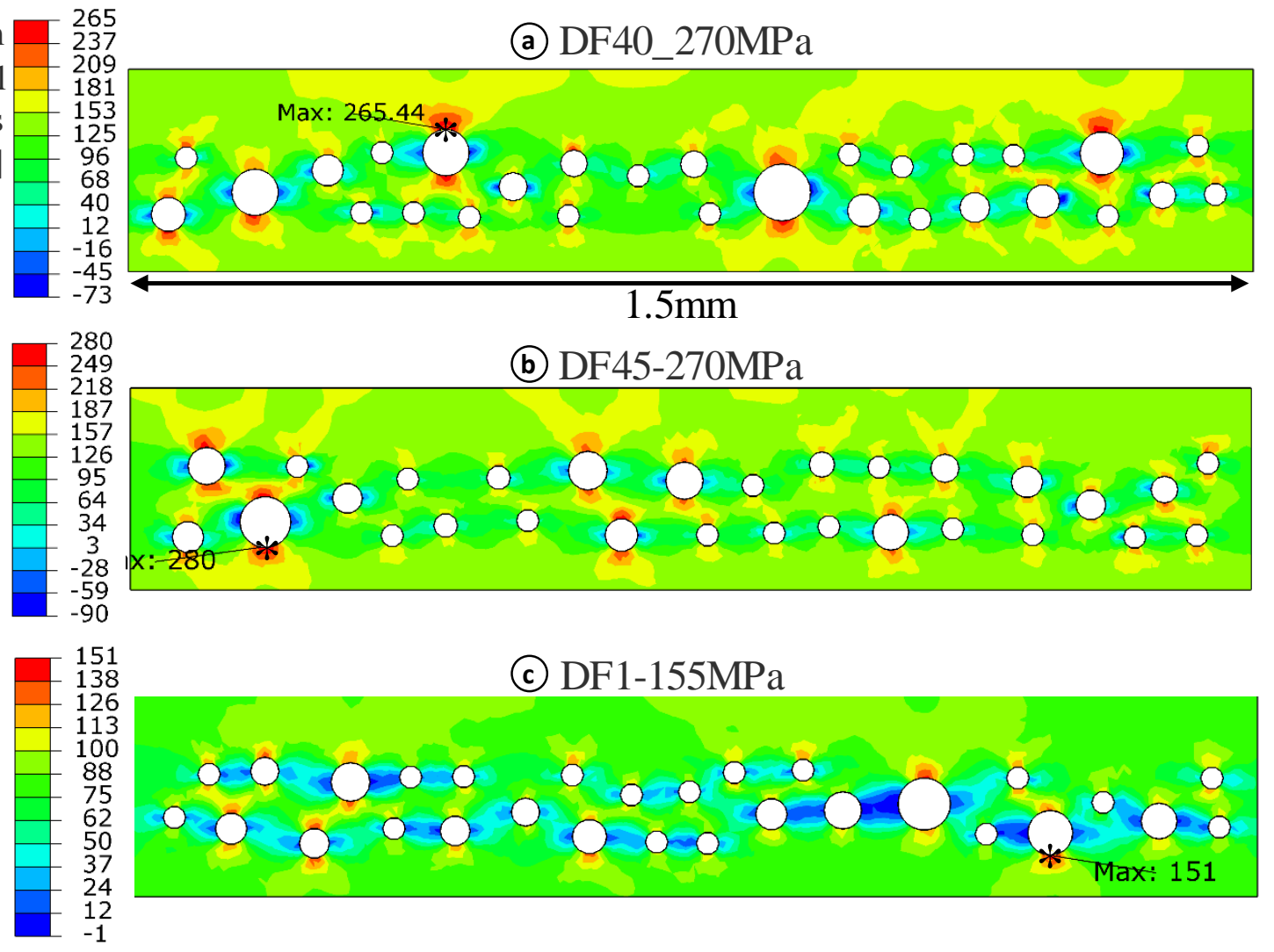

$x:-280$

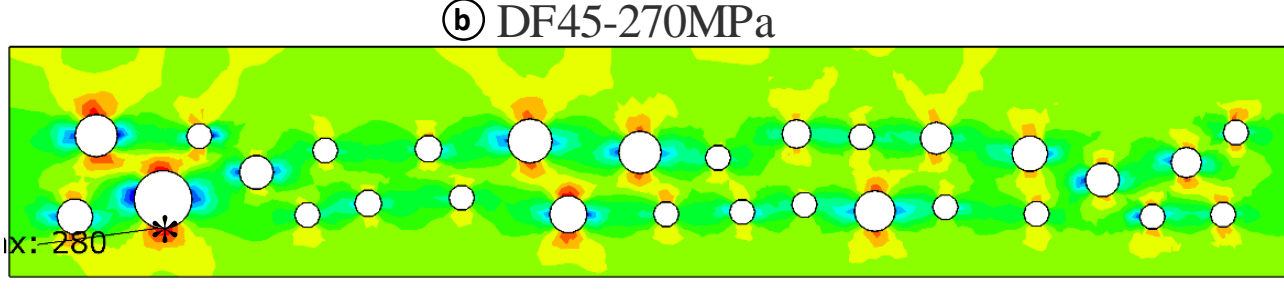

(c) $\mathrm{DF} 1-155 \mathrm{MPa}$

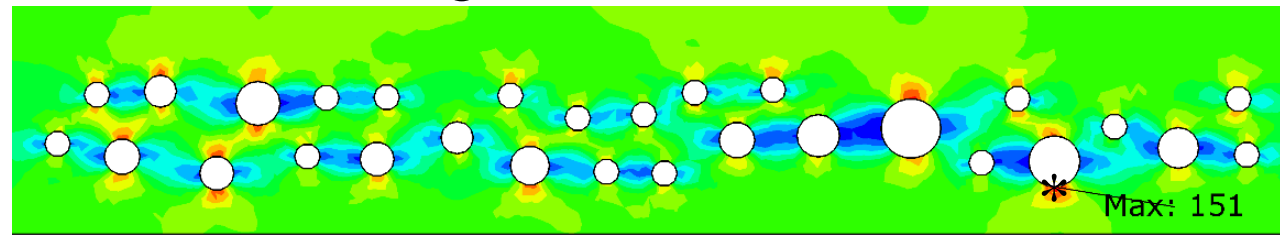

(d) $\mathrm{DF} 3-155 \mathrm{MPa}$

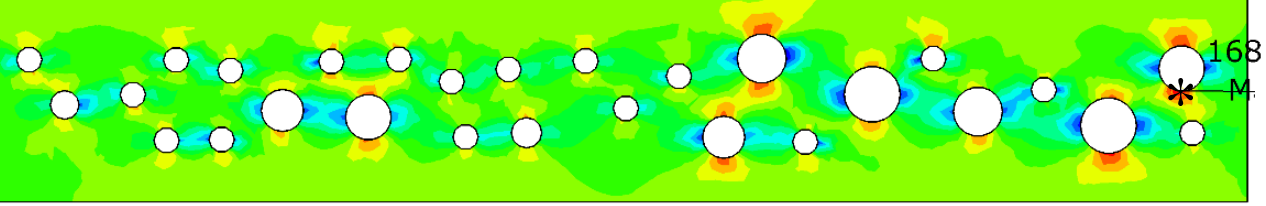




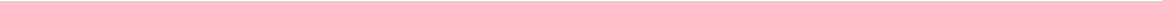



$-0.5$
$-0.25$
$2 a \quad 0$
0.25
0.5

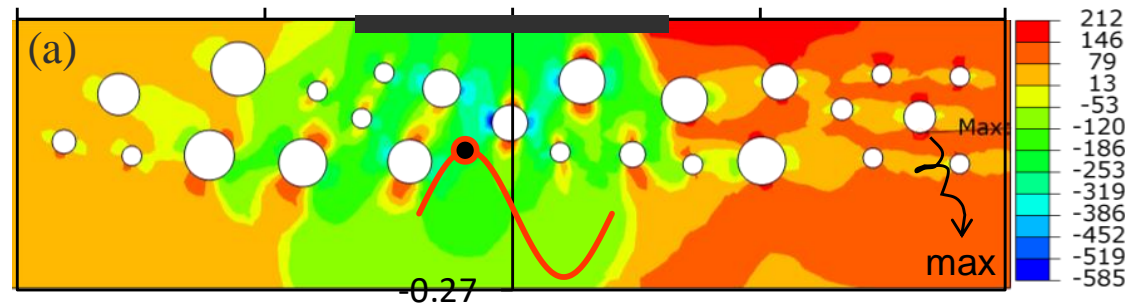
$-0.5$
$-0.25$
0
0.25
0.5

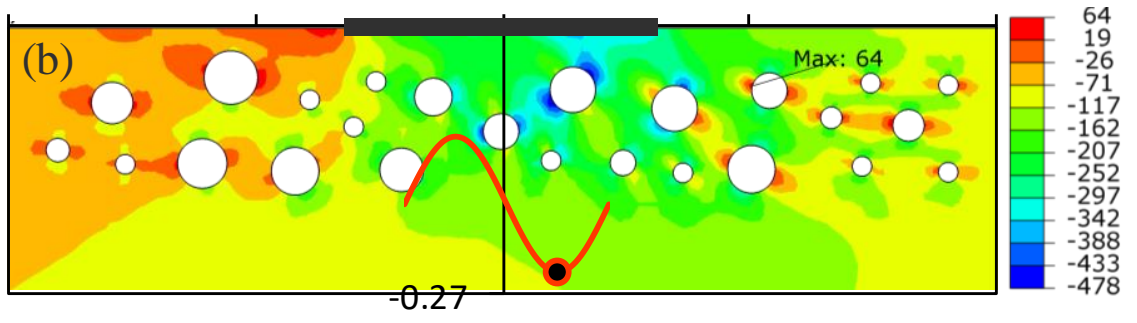

$-0$.

$-0.25$

0

0.25

0.5

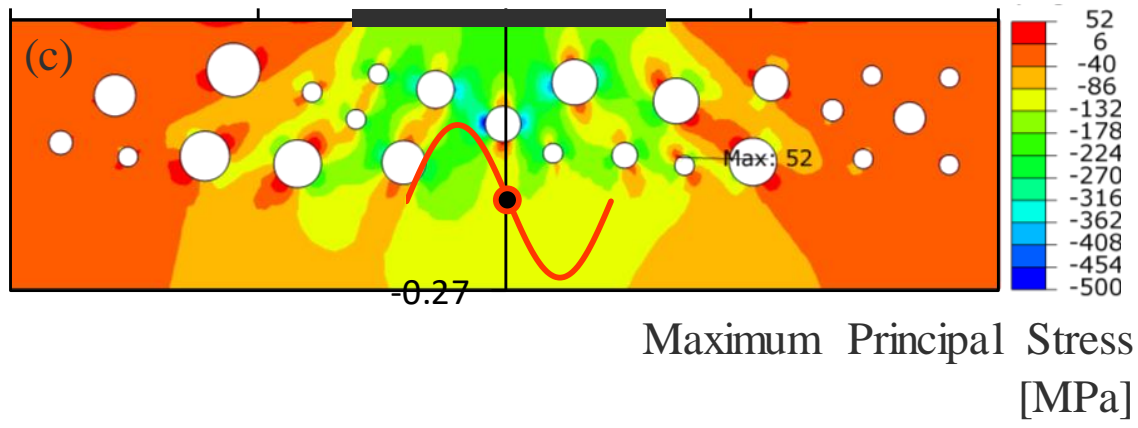




\section{$\sigma_{x x}[\mathrm{MPa}]$}

- - - HP-D5-50MPa

—. HP-D4-50MPa

* - - HP-D3-50MPa HP-D2-50MPa

* - - HP-D1-50MPa

O Ref.

300

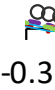

3 
Contact line [mm]

$\begin{array}{lll}-0.3 & -0.1 & 0.1\end{array}$

0.3

teococoscosepes

- - - HP-D5-50MPa

-.. HP-D4-50MPa * - - HP-D3-50MPa HP-D2-50MPa * - - - HP-D1-50MPa

O Ref.

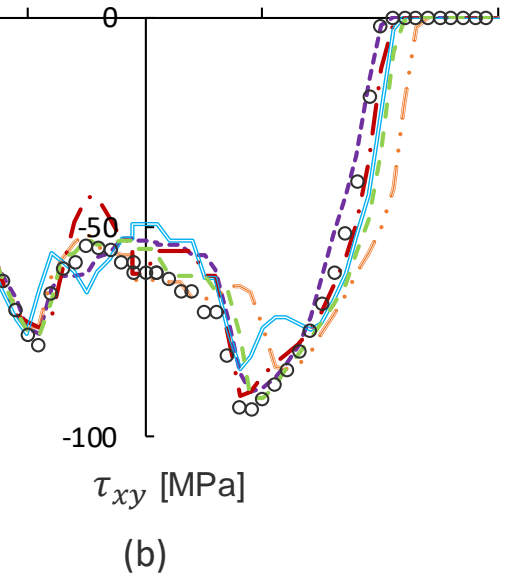


Contact line [mm]

$\begin{array}{lllllll}-0.3 & -0.2 & -0.1 & 0 & 0.1 & 0.2 & 0.3\end{array}$

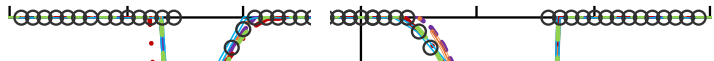

- - - HP-D5-50MPa

- HP-D4-50MPa

* - - HP-D3-50MPa

HP-D2-50MPa

* - - HP-D1-50MPa

○ Ref.

0.15 Slip [um] 


\section{$\sigma_{x x}[\mathrm{MPa}]$}

*----- HP-D25-90MPa 300

* -..HP-D24-90MPa

- - HP-D23-90MPa

* HP-D22-90MPa

* - - - HP-D21-90MPa

○ Ref.

200
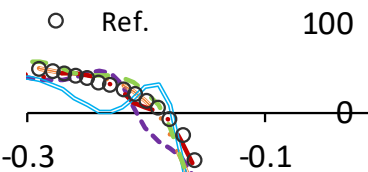
Contact line [mm]

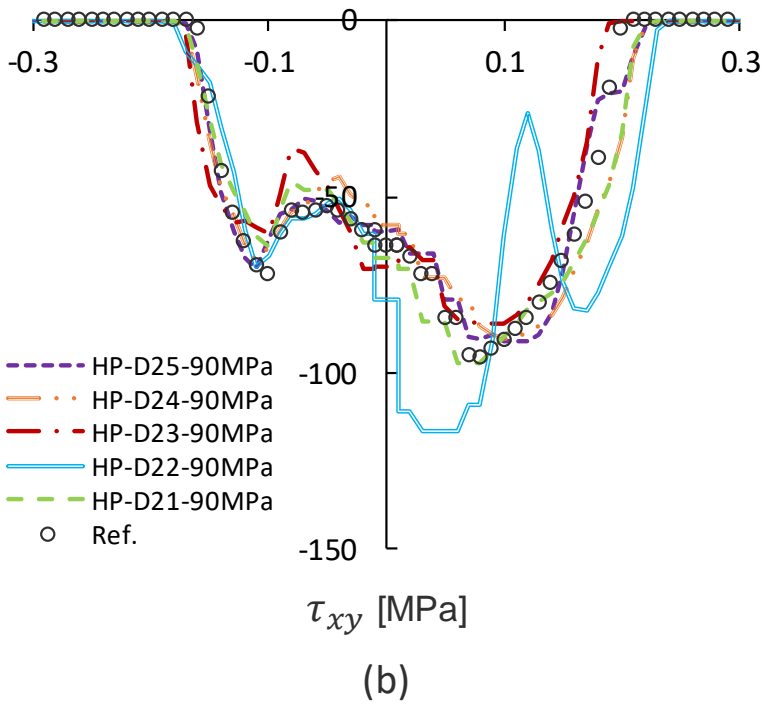


$-0.3$

$-0.1$

0.1

0.3

'œ000000000000

* - - - HP-D25-90MPa

* - . HP-D24-90MPa - - HP-D23-90MPa * $\longrightarrow \mathrm{HP}-\mathrm{D} 22-90 \mathrm{MPa}$ * - - HP-D21-90MPa o Ref.

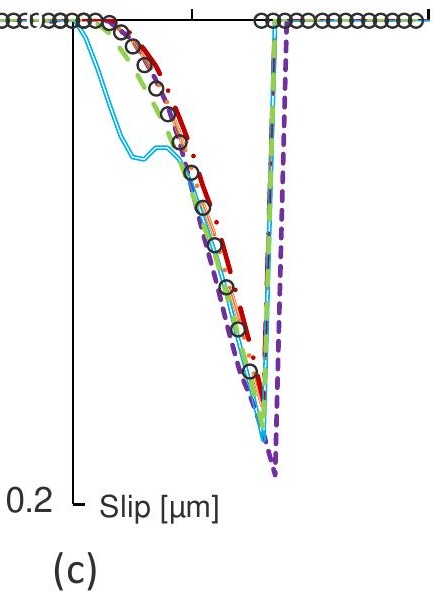


